\title{
El PERÍOdo Formativo de TARAPACÁ Y SU CERÁmica: Avances sobre complejidad Social en la costa del Norte Grande De Chile (900 AC-800 DC)
}

\author{
Mauricio Uribe R. ${ }^{1}$
}

\section{$*$ Introducción}

Resumen

Se aborda la emergente complejidad social en la costa de Tarapacá (Iquique y desembocadura del río Loa) durante el Formativo Tardío para aportar a la discusión de las interpretaciones vigentes, identificando aquellos aspectos cualitativos significativos que provee el análisis cerámico. Proponemos que, si bien las primeras comunidades con alfarería aparecerían hacia $900 \mathrm{AC}$, es entre 200-800 DC que éstas intensifican el proceso de exploración, asentamiento y explotación de los recursos locales sobre la base

de las prácticas arcaicas costeras articuladas con el interior, y manteniendo alta movilidad, logrando una amplia distribución con un marcado ceremonialismo. En este escenario se definiría una complejidad social propia, donde las innovaciones agrícolas, cerámicas u otras se vuelven lógicas, sin mostrar una dependencia de agentes externos colonizadores ni limitada por las condiciones áridas del medio ambiente.

Palabras claves: cerámica - período Formativo - complejidad social - Tarapacá - norte de Chile.

Abstract

This paper contributes to the debate on the emergence of social complexity during the Late Formative in the coast of Tarapacá (Iquique and Loa river mouth) by identifying the more significative qualitative aspects provided by ceramic analysis. Although the first communities with pottery appear in $900 \mathrm{BC}$, between $\mathrm{AD} 200-800$, they were intensifying their exploration, settlement and exploitation around local resources on the basis

of archaic coastal practices articulated with the inland, while keeping to intense mobility patterns that reaches a widespread distribution with strong ceremonial content. This scenario defines a particular form of social complexity whereby agricultural, ceramic and other innovations were the logical outcome of local knowledge and practices, neither dependent on foreign agents or sources, nor constrained by the arid environment.

Key words: pottery - Formative period - social complexity Tarapacá - Northern Chile.

Recibido: mayo 2008. Aceptado: diciembre 2008.
Siguiendo las primeras apreciaciones de Uhle (1922), Latcham planteaba que la alfarería hacía su aparición en la costa de la "región atacameña" antes y durante la época de Tiwanaku, uno de cuyos centros habría sido Pisagua, donde sería más bien "primitiva" (1938:223), distinguiéndose piezas de fondo cónico, semicónico y redondeado. Coincidente con lo anterior, Bird (1943) identificó cerámica temprana en los fragmentos del Conchal Café o Brown Refuse, correspondiente a lo que denomina "pucos" con antiplástico de arenisca, engobe rojo y bordes engrosados, que hoy podrían relacionarse con vasijas restringidas como cántaros con borde "en coma", típicos del Formativo, especialmente temprano (Uribe y Ayala 2004; Uribe 2006a). Junto con ellas destacarían otras ollas de diversas formas y colores que varían entre café, rojo y negro, algunas pulidas (Bird 1943). La misma cerámica no decorada y sin engobe continuaría en el Conchal Negro o Black Refuse con "pucos" u ollas de boca ancha, base plana y ennegrecidos por exposición al fuego, observándose la ausencia de los bordes engrosados tempranos. Así, el autor considera esta alfarería monocroma como antecesora de las cerámicas I y II de Arica, pudiendo también ser contemporánea a las épocas "Tiwanaku” y “Tiwanaku Atacameño" de Uhle y Latcham (Schaedel y Munizaga 1957: 73).

En consecuencia, desde los inicios de la arqueología chilena hay constancia de alfarería temprana en la región de Tarapacá, particularmente concentrada en

\footnotetext{
${ }^{1}$ Departamento de Antropología, Universidad de Chile. Ignacio Carrera Pinto 1045, Ñuñoa, Casilla 10115, Santiago, CHILE. Email: mur@uchile.cl
} 
su costa, permitiendo abordar el problema del origen de esta tecnología y la complejidad social vinculada al cambio cultural que implica, un tema todavía inconcluso y no exento de polémica dentro del Norte Grande de Chile (Muñoz 1989, 2004, 2005; Rivera 1988-89). Todo esto ha generado una gran discusión en torno al período Formativo de los Valles Occidentales y los denominados complejos culturales Faldas del Morro y Alto Ramírez, a la cual deseamos aportar con nuestro trabajo en la costa de Iquique, entre Pisagua y el río Loa (Figura 1). Para ello, asumimos que a pesar de las condiciones hiperáridas de este territorio, se hallarían algunas de las evidencias más antiguas de su aparición; pero, más allá del problema cronológico, nos interesa porque el desarrollo diacrónico de esta materialidad permite reflexionar acerca de sus consecuencias sociales para entender los procesos de complejidad que han experimentado estas poblaciones (Uribe 2006b; Uribe y Adán 2008).

\section{* Antecedentes sobre la cerámica y el Formativo de Tarapacá}

Núñez y Moragas (1983) han sido prácticamente los únicos en desarrollar trabajos especializados sobre la cerámica del litoral tarapaqueño. ${ }^{2}$ En especial, destaca su estudio de la alfarería temprana del asentamiento costero Cáñamo, al sur de Iquique, en el que intentan esclarecer a través de una tipología las relaciones entre la aparición de la cerámica, la agricultura inicial y el desarrollo de las redes de intercambio a larga distancia. Ello con el fin de entender la complejidad social que fue adquiriendo este proceso durante la llamada fase Cáñamo II o Cáñamo Montículo. En general, su análisis combina la clásica descripción arqueológica con análisis mineralógicos y petrográficos de las muestras (p.e., cortes delgados y difracción de rayos $\mathrm{X}$ ) que, además, comparan con una evaluación geológica del lugar en estudio. El examen fue practicado sobre fragmentos provenientes de depósitos estratificados y bien fechados

\footnotetext{
2 Aunque más básico, y centrado en el material del sitio Caserones 1, al interior de Tarapacá, también se debe mencionar el estudio tipológico y morfológico realizado por Mavrakis (1985).
}

(por radiocarbono y termoluminiscencia), cuya clasificación se centró en una caracterización de pastas, superficies y formas. No obstante, no se explicitan los parámetros con que establecieron la variabilidad de tales atributos, dificultando la comprensión de los tipos propuestos. Estos fueron los tipos Cáñamo Alisado homogéneo e Imperfecto, correspondientes a ollas con hollín, con cuello evertido corto y cuerpo esférico, elaboradas con pastas arenosas aunque densas en cuarzos gruesos y cocción irregular. A éstos se suman los tipos Cáñamo Café estriado fino y Paleteadoestriado también con pastas arenosas, pero más finas y de formas diferentes. En el primer caso, se trataría de vasijas semejantes a las anteriores, aunque de cuellos largos y bordes bastante delgados que probablemente refieren a cántaros o contenedores de líquidos, incluso de morfología asimétrica. En el segundo, se trataría de bordes directos levemente inflectados cerca del labio, también bastante delgados que, en cambio, refieren a platos o tazones, sin asas ni decoración, a veces con engrosamiento del labio o labio en coma. Por último, identificaron el tipo Cáñamo Café pulido que comparte las pastas arenosas y el predominio de cuarzos, sin embargo, no se pudieron definir formas (Núñez y Moragas 1983).

De este modo, la totalidad del material refiere a alfarería de cocina y uso doméstico, seguramente de producción familiar, donde las ollas alisadas serían mayoritarias (67.24\%), mientras que los tipos estriados y paleteados serían bastante minoritarios, al igual que los pulidos $(4.42 \%)$, respectivamente. Lo anterior es complementario a la concentración de la cerámica alisada en los primeros estratos, fechados por radiocarbono (no calibrados) y termoluminiscencia entre 860 y $810 \mathrm{AC}$, señalando una ocupación en el Formativo Temprano sobre otra del Arcaico Tardío en la cual se insertarían los primeros fragmentos alisados, asociados a maíz y culminando en la superficie con la incorporación de la cerámica pulida (Núñez y Moragas 1983; Moragas 1995). Sin embargo, se aprecia una importante arbitrariedad en la documentación de los datos estratigráficos y frecuencias, así como falta de claridad en la descripción que incide, nuevamente, en una difícil representación de los tipos cerámicos y su comportamiento. 


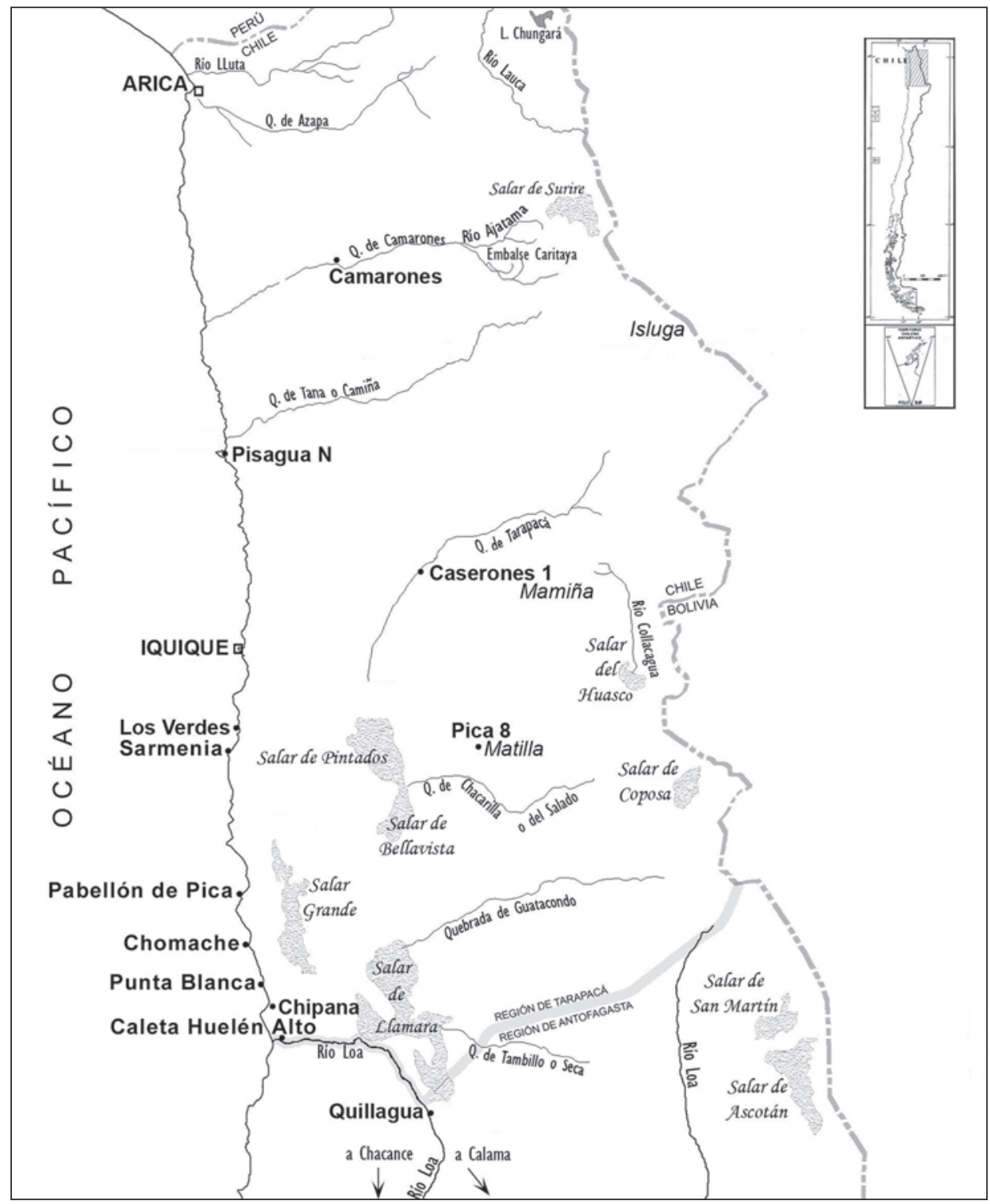

Figura 1. Mapa de la región de Tarapacá que indica los principales sitios mencionados en el texto.

En este sentido, resultan mucho más interesantes los análisis mineralógicos y petrográficos realizados, que ayudan a introducirse en el proceso productivo $y$ en la circulación de esta cerámica (en lo que refiere al problema de su origen local o foráneo) y su relación con elementos y procesos compartidos con otras expresiones centro sur andinas, en especial del Formativo del Altiplano Meridional. Para los autores, según estos análisis, una de las primeras tradiciones cerámicas que llegó a la costa desértica del norte chileno fue la café alisada, proveniente de alguna población relacionada con la cultura Wankarani de Bolivia, cuya tecnología fue adoptada plenamente por las poblaciones marítimas de Chile, ya sea por contacto directo o indirecto con las comunidades altiplánicas (Núñez y Moragas 1983).

No obstante, dichos análisis pudieron ser aún más provechosos, sobre todo para validar estos supuestos acerca de los primeros desarrollos con alfarería del norte chileno, puesto que a falta de evidencias de los procesos experimentales e iniciales, la tecnología cerámica y específicamente los estudios de pasta 
ofrecen una adecuada alternativa para abordar el origen o la difusión como parte de este proceso (Barnett y Hoopes 1995). De hecho, resulta contradictorio que al mismo tiempo que se propone un ingreso altiplánico se considere a toda esta alfarería como parte de "una sola familia cerámica" (Núñez y Moragas 1983: 48), sugiriendo también un origen local, que es coincidente con sus mismos análisis mineralógicos y petrográficos. Al respecto, los tipos alisados mostrarían materias primas claramente costeras, mientras que los estriados y pulidos presentarían componentes volcánicos del interior y/o mixtos, confirmando que la movilidad pudo haberse restringido al litoral y a las quebradas bajas al oriente de la Pampa del Tamarugal (o-1500 $\mathrm{m}$. snm), sin tener que acceder o contactarse necesariamente con el altiplano. Asimismo, la alfarería con componentes interiores puede estar reflejando una ocupación posterior, relacionada con los tipos formativos tardíos e incluso del desarrollo regional preincaico (complejo cultural Pica-Tarapacá), donde predominan los estriados o rasmillados junto a los pulidos (Uribe et al. 2007), por lo que además se hacen necesarios más fechados por radiocarbono y termoluminiscencia para apoyar sus aseveraciones.

En este sentido, adquiere relevancia la discusión de las evidencias formativas en la desembocadura del río Loa, si bien mayormente relacionadas con las manifestaciones funerarias y, en particular, con sus túmulos en Caleta Huelén (Núñez 1971; Moragas 1995). Para los sitios tumulares Caleta Huelén 7, 10, 20 y 43, fechados entre $450 \mathrm{AC}$ y $820 \mathrm{DC}$ (radiocarbono no calibrado), se documenta cerámica correspondiente a ejemplares monocromos alisados, burdos y pulidos rojos, negros y grises, en gran parte concentrados en momentos tempranos, anteriores a 215 DC. La mayoría de los contextos tendrían un carácter marítimo, reconociéndose que la introducción de elementos del interior sería bastante menor, aunque se insiste en la existencia de rasgos altiplánicos (p.e., cobre, maíz y quínoa). Así, dichos contextos serían el producto de desplazamientos poblacionales desde el interior a través de los cursos fluviales hacia la costa, a modo de "corredores", donde los túmulos no aparecerían o serían muy escasos al alejarse de tales cuencas (Moragas 1995: 70). ${ }^{3}$ De esta manera, la evidencia cerámica -así como otros elementos culturales-es concebida como expresión de cierta diversidad de comunidades formativas al registrarse tipos tanto alisados como pulidos, los que a su vez aparecen en contextos únicos o mezclados, aludiendo a flujos de población resultantes de movimientos expansivos de los desarrollos Wankarani, Chiripa y Pukara del Altiplano Circumtiticaca, los que utilizando valles y oasis intermedios de Tarapacá, accedieron a la costa por donde se desplazaron longitudinalmente privilegiando los espacios agrícolas más ricos y enfrentando ajustes de adaptación al medio ambiente marítimo (Moragas 1995). Conforme a lo anterior, dichos grupos habrían llegado tempranamente a las tierras bajas y costeras, motivados por presiones demográficas y con un interés agrícola bien definido que les llevaría a moverse a través de las cuencas y asentarse en zonas fluviales, privilegiando las desembocaduras. Allí, sobre una base arcaica de caza y recolección, accederían a la riqueza marítima que los motivó a quedarse de manera permanente (Núñez 1971). Bajo estas condiciones, se habría consolidado un modo de vida agromarítimo inicial, sustentable dentro de ciertas limitantes demográficas, pero que al crecer, y debido a la dificultad de expandir el desarrollo agrícola en la costa arreica, a la par de su auge en el interior, habría girado hacia una especialización marítima que se volvió dependiente de "cabeceras" agrícolas en los valles, dando paso al desarrollo regional tardío con un intenso intercambio (Núñez 1971: 20).

Desde esta perspectiva, las situaciones formativas al interior de Tarapacá también adquieren importancia en esta discusión. La alfarería costera, tanto doméstica como funeraria, mantendría vínculos claros con

\footnotetext{
3 Si bien una buena parte de los túmulos se concentra cerca de zonas de desembocadura (p.e., Camarones, Tana-Tiliviche y Loa), gracias a nuestras prospecciones sistemáticas, hoy sabemos que en el litoral de Iquique las mismas manifestaciones adquieren una distribución más amplia y bastante alejada de dichas cuencas. Por otra parte, la existencia de túmulos en otras zonas del interior, como Quillagua (Agüero et al. 1995, 2001, 2006), hace discutible el vínculo directo entre la costa y el altiplano.
} 
la aldea de Caserones o Caserones 1 (Núñez 1966, 1982), la que presenta componentes cerámicos similares referidos a tipos alisados y pulidos, sin asas ni decoración, principalmente locales, aunque también se ha postulado un origen foráneo, sobre todo para la alfarería pulida (Mavrakis 1985). En esta dirección, resulta interesante el estudio de Kautz y colaboradores (1980), por cuanto hasta ese momento era el único que había experimentado con técnicas fisicoquímicas de alta precisión para el análisis de cerámica (p.e., fluorescencia de rayos X), al menos en el norte de Chile. Inmersos en un programa de investigación chileno-norteamericano sobre el sitio Caserones 1 que fue ocupado por más de 2000 años (1000 AC1200 DC), evalúan la clasificación alfarera del sitio, realizada a partir de criterios de forma y tratamientos de superficie (Núñez 1965, 1966; Mavrakis 1985).

Dicha clasificación había propuesto de cinco a seis clases cerámicas, las cuales proveían de información acerca de los movimientos poblacionales, los contactos e influencias culturales ocurridas a lo largo de la ocupación de Caserones. Según Núñez (1965), la cerámica permitía distinguir que dentro de una alfarería mayoritariamente local, se introducían elementos foráneos, en particular cerámica negra pulida vinculada con los desarrollos culturales de los oasis de Atacama. Con el fin de evaluar estas inferencias y la metodología utilizada para llegar a ellas, el equipo norteamericano aplicó el análisis de fluorescencia de rayos $\mathrm{X}$ a una serie de muestras de esos tipos cerámicos, utilizando el ciclotrón de la Universidad de California y técnicas estadísticas para establecer los resultados (p.e., coeficiente de correlación Tau de Kendall y coeficiente de similitud de Sokal y Michener). Gracias a eso se concluyó, si bien de manera aún preliminar según los propios autores, que la muestra de cerámica de Caserones tenía un origen local. Esto no significaba que toda la alfarería era igual, pero sí que su materia prima provenía de la localidad, cuestionándose con ello las conexiones a larga distancia establecidas con Atacama, al menos a través del tráfico directo de las piezas cerámicas.
En consecuencia, asumiendo las deficiencias técnicas respecto al muestreo, la falta de trabajos sistemáticos sobre la alfarería en el sitio, y del resto de sus características, coincidimos con Kautz y colaboradores (1980) en que metodologías como las empleadas para Caserones pueden brindar información significativa para afinar las interpretaciones hechas a partir de la cerámica. En este caso preciso, dichas interpretaciones claman por una reflexión más acabada y por el replanteamiento sobre el sistema de producción local en el paso de una estructura social familiar a otra comunal, en momentos del ingreso de la alfarería a la región y posteriores. Paralelamente, a pesar de ser bastante cualitativas, son interesantes las apreciaciones de Mavrakis (1985), quien con estos antecedentes, a partir de su análisis tipológico y evaluación estratigráfica plantea para Caserones un proceso creciente de complejización social que habría llegado a su clímax en el período III (o-60o DC). Para esos momentos, en forma coincidente con los trabajos de True (1980) en el poblado, aprecia el predominio de tipos alisados, pulidos y engobados, especialmente en las capas intermedias e inferiores. Luego, en el período IV (60o-80o DC) observa muy poca cerámica pulida y un considerable aumento de la alisada hacia la superficie, donde los tipos pulidos casi desaparecen. En este marco, la población local habría experimentado la jerarquización social a la par de la especialización económica en gran escala, por ejemplo en la agricultura, el tráfico de intercambio y la alfarería (Núñez 1982), aunque causas más internas que externas habrían actuado para hacer de Caserones un asentamiento de características casi urbanas (Mavrakis 1985). Ya sea bajo una u otra perspectiva, lamentamos que tales investigaciones no hayan tenido continuidad en el tiempo, impidiéndonos convertir estas estrategias en una práctica más común dentro de la arqueología de esta parte del Norte Grande.

Una situación parecida se ha planteado para el asentamiento aldeano Guatacondo I, al sur de Tarapacá, así como para Ramaditas, al oeste del anterior. Para el primero se ha descrito cerámica sin decoración con una fecha inicial de 60 DC y final de 1175 DC (radiocarbono no calibrado), con pastas granulosas y arenosas, de no más de $1 \mathrm{~cm}$ de grosor, cocción 
irregular, cuyo tratamiento de superficie varía de alisado a pulido imperfecto, con formas restringidas de borde evertido, a veces con labio engrosado en coma, que refieren a ollas y jarros o cántaros sin asas (Mostny 1970; Meighan 1980). Las mismas piezas, sobre todo las espatuladas y algunas figurillas, incluso podrían aparecer hacia 806-755 cal. AC y permanecer hasta $90 \mathrm{AC}$ (sin calibrar) en los asentamientos de Ramaditas (Rivera et al. 1995-96; Rivera 2005). En este caso se afirma que un proceso previo a Tiwanaku, política e ideológicamente dependiente de la subárea circumlacustre, se habría desarrollado aquí y operado a base del conocimiento hidráulico mantenido y ejercido por determinadas élites religiosas (Rivera 2005).

Un poco más tardíamente, en el cementerio Tarapacá $40 \mathrm{~A}$, con fechados absolutos no calibrados de 290 y 360 DC (Núñez 1969), se encontraron escasas vasijas correspondientes a pequeños contenedores a modo de cuencos y platos hondos de color café; junto a una pieza mayor de forma restringida semipulida y de color gris, con borde evertido y cuerpo esférico, a la que se agregaron pequeñas asas en arco, al parecer de suspensión, en lados opuestos del cuello y con decoración punteada. Asociado al anterior, el cementerio Tarapacá 4 OB se considera un sector aún más tardío pero donde la alfarería sigue siendo burda, distinguiéndose una familia de cerámica café alisada con bordes evertidos, cuello estrecho y corto, con cuerpos esféricos a ovoides, correspondientes a jarros o cántaros; además de otras vasijas café alisadas pero de forma restringida simple, como cuencos u ollas. Por otra parte, se diferencia una familia de cerámica gris, negra y roja pulida donde se integran vasos y tazones troncocónicos con base plana. Por último, se destaca un grupo de miniaturas no cocidas, al que también se integran tapas para pequeños contenedores de harinas y discos usados como platos y figurillas (Núñez 1967-68; Núñez y Moragas 1983).A estas evidencias funerarias se pueden sumar los sitios Pica-Quisma y Pica-Tenencia, en el oasis homónimo (Moragas 1995; Sanhueza 2005), cuyos contextos todavía son muy poco conocidos, pero que han sido interpretados desde dos perspectivas distintas, abriendo el debate en relación a los modelos que han intentado explicar el Formativo de la región. En el primer caso se mantiene la idea de una penetración altiplánica que coloniza valles y oasis para luego pasar a la costa, mientras que en el segundo se valoriza el sustrato local y arcaico, acercándose a los planteamientos que desarrollamos en este artículo.

No obstante, por mucho tiempo la cerámica monocroma café, gris, negra y roja, alisada, pulida, espatulada o paleteada, a veces con bordes en coma y presencia de figurillas, fue aceptada como manifestación de un temprano proceso de expansión altiplánica ocurrido entre 900 y $800 \mathrm{AC}$, alcanzando el litoral del Pacífico incluso antes de 1000 AC. Se concluyó que lo más parecido a la alfarería de sitios como Cáñamo, Caserones y Guatacondo eran las cerámicas de Wankarani y las primeras expresiones de Chiripa, situación que se extendería por la costa tarapaqueña desde Camarones, Pisagua y el Loa hasta Cobija, intermediando en ello los valles y oasis interiores asociados a la Pampa del Tamarugal (Núñez 1966, 1967-68, 1970, 1971, 1982, 1984; Moragas 1982, 1995; Núñez y Moragas 1983; Rivera 1988-89, 2002, 2005; Aufderheide et al.1994).A algunas de estas manifestaciones, además, se agregarían elementos relacionados con San Pedro de Atacama y el Noroeste Argentino, como los encontrados en Pircas y Caserones, al menos desde 500 AC (Núñez 1984; Mavrakis 1985), pero siempre bajo un predominio poblacional y una dependencia ideológica y política con el Altiplano Circumtiticaca.

\section{* La cerámica de la costa tarapaqueña DURANTE el período Formativo}

Sobre la base de nuestros trabajos en Tarapacá y Quillagua (Ayala y Uribe 2003; Uribe y Ayala 2004; Agüero et al. 2006; Uribe et al. 2007; Ayala et al. 2008; Uribe $2008 \mathrm{Ms}$ ), no nos parece satisfactoria la concepción sobre el período Formativo de la región que se ha mantenido vigente, por lo cual deseamos contribuir a la discusión a través del análisis de la alfarería de algunos asentamientos que estamos estudiando en la costa arreica de Iquique (Schaedel y Munizaga 1957; Spahni 1967; Núñez 1971; Sanhueza 1985; Moragas 1995). 


\section{Caracterización actualizada de la cerámica formativa tarapaqueña}

En términos sucintos, actualmente reconocemos dos expresiones cerámicas para el Formativo de Tarapacá (Figura 2), sin vinculaciones con el altiplano ni con Wankarani, destacando una alfarería inicial y otra más tardía (Ayala 2001; Uribe y Ayala 2004). En primer lugar, hemos registrado cerámica con todas las características que se mencionan para una industria inicial de vasijas con bordes en coma (Figura 3), la cual hemos confirmado con fechados absolutos (TL) de 730 y 530 AC en Quillagua, denominándola tipo Loa Café Alisado (Agüero et al. 2001, 2006; Uribe y Ayala 2004; Uribe 2006a). Aunque muy ocasional, alcanza una amplia distribución geográfica, por lo cual también suele asignarse a "Alto Ramírez" (Rivera 1988-89, 2002; Sinclaire et al.1998; Ayala 2001), en especial por compartir la misma solución técnica del engrosamiento del labio, pero sin ser necesariamente un mismo tipo. Gallardo y colaboradores (1991) aportan fechas de 220 y 270 DC para otros ejemplares con bordes en coma de Quillagua, sugiriendo un momento contemporáneo con la cerámica que parece popularizarse después de 200 DC y que constituye la segunda expresión que caracterizaremos a continuación.

Por una parte, definimos como predominante un tipo Quillagua Tarapacá Café Amarillento o QTC (Munsell Soil Color Charts 1oYR $7 / 3,7 / 2$ y 6/3, 2.5 Y 6/2), identificado principalmente en los cementerios Tarapacá 40A y B, pero también en Pica (Moragas 1995) y en sitios de Quillagua, donde alcanza el 23\% que, en Caserones 1, asciende a 33\% (Uribe y Ayala 2004; Uribe et al. 2007). Este tipo se caracteriza por pastas diversas en términos de color y por una heterogeneidad de inclusiones las arcillas (minerales, restos orgánicos e incluso greda o cerámica molida). De este modo, se reconocen vasijas

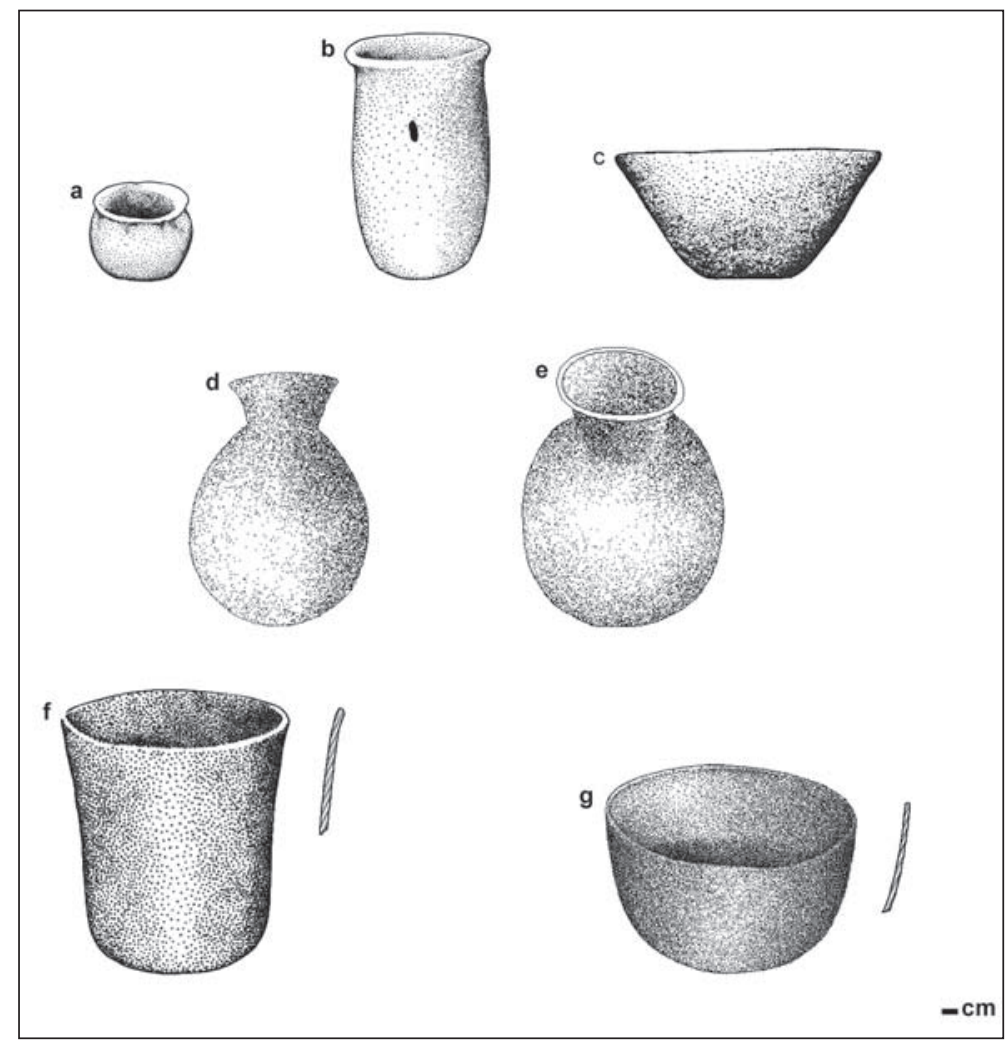

Figura 2. Tipos cerámicos del período Formativo de Tarapacá (reconstrucción de formas completas): a-c) Tipo Quillagua Tarapacá Café Amarillento (QTC); d-e) Tipo Quillagua Rojo Pulido (QRP);

f-g) Tipo Caserones Negro Pulido (CNP). 


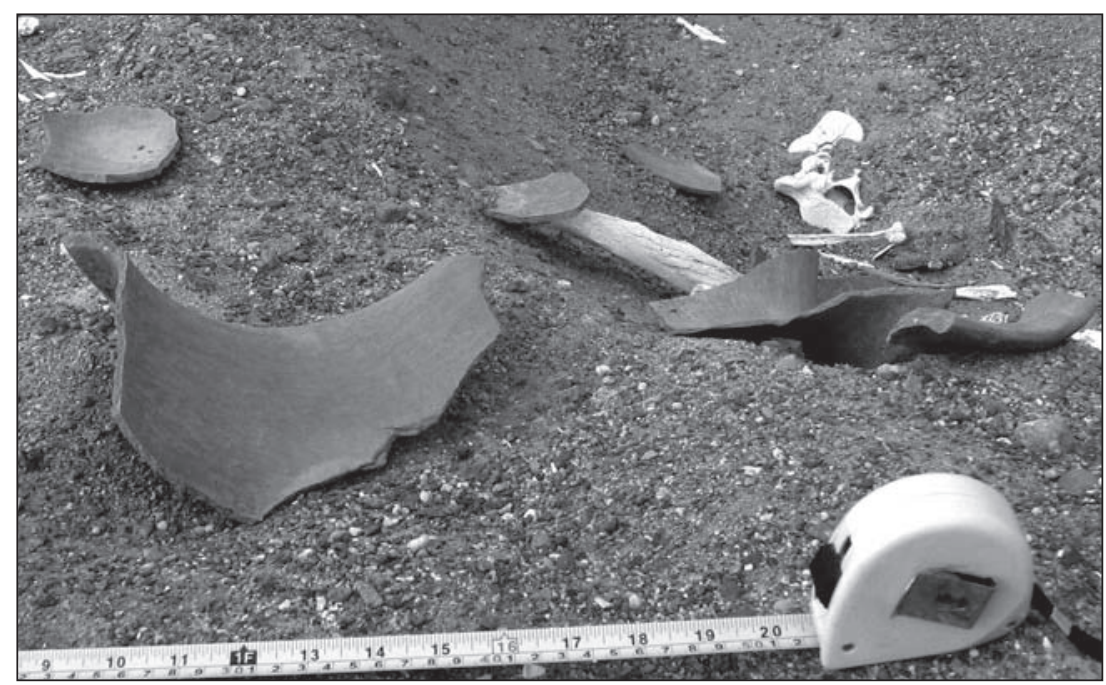

Figura 3. Tipo cerámico Loa Café Alisado (LCA). La fotografía muestra bordes engrosados o "en coma" en un contexto funerario disturbado en la localidad de Chipana.

restringidas simples y no restringidas, en su mayoría pequeños cuencos, a los que se agregan aquellos con una leve inflexión en el cuello (pocillos), ollas o "vasos-floreros" dependiendo del largo y ancho del cuerpo (Figura 4). Las superficies fueron dejadas en estado de "cuero", mostrando el raspado o espatulado provocado por instrumentos, las huellas de los dedos del artesano, e improntas de cestería en las bases. Complementariamente, se constatan discos usados como tapas de vasijas, amarrados con fibras vegetales para asegurar el contenido, demostrando su uso como recipientes ceremoniales u ofrendas de alimentos.

En general, estos recipientes provenienen de cementerios y de túmulos, y tendrían un destino ritual, festivo y funerario, ya que al parecer fueron creados exclusivamente para ese fin, pues la mayoría corresponde a miniaturas que a veces no superan los $2 \mathrm{~cm}$ de alto, sin tratamiento de superficie y sin cocer, o bien, el proceso fue demasiado rápido, deficiente, muy irregular o incompleto a pesar de hacerse en ambiente oxidante. Sin embargo, también hay piezas bien cocidas con superficies revestidas rojas y pulidas, aparte de variantes más locales que incluyen vasijas restringidas con decoración punteada en el labio, no restringidas como tazones o vasos, y otras de cuerpo asimétrico con borde irregular terminado en vertedera.
Estas últimas fueron individualizadas como variedad Quillagua Café Amarillento o QCA, mientras que las punteadas las asignamos al grupo Tarapacá Café Punteado o TCP (Uribe y Ayala 2004).

A la anterior se suma la cerámica pulida, que es escasa pero recurrente, ya que su frecuencia fluctúa entre $10 \%$ y $4 \%$ en Caserones y Quillagua, respectivamente (Uribe y Ayala 2004; Uribe et al. 2007). Esta podría constituir otra variedad de alfarería tarapaqueña, pues sus materias primas no son muy distintas, aunque tampoco descartamos un vínculo con la cerámica pulida de Atacama que ocasionalmente aparece en la región durante este período (p.e., piezas San Pedro Negro Pulido con modelado antropomorfo naturalista). En cualquier caso, nos inclinamos por un desarrollo local, ya que además esta cerámica comprende formas semejantes a las de Atacama, por lo que preferimos llamarlo tipo Quillagua Rojo Pulido o QRP, ya que fue allí donde lo observamos por primera vez. Esta alfarería presenta pastas arenosas como las de Tarapacá, pero más compactas y homogéneas, de cocción oxidante y fractura regular a angular. Comprende formas no restringidas simples y complejas, como vasos troncocónicos e inflectados con mamelones o protúberos, respectivamente; en tanto, las restringidas refieren a botellas de cuerpo esférico y elíptico con cuello cilíndrico, 


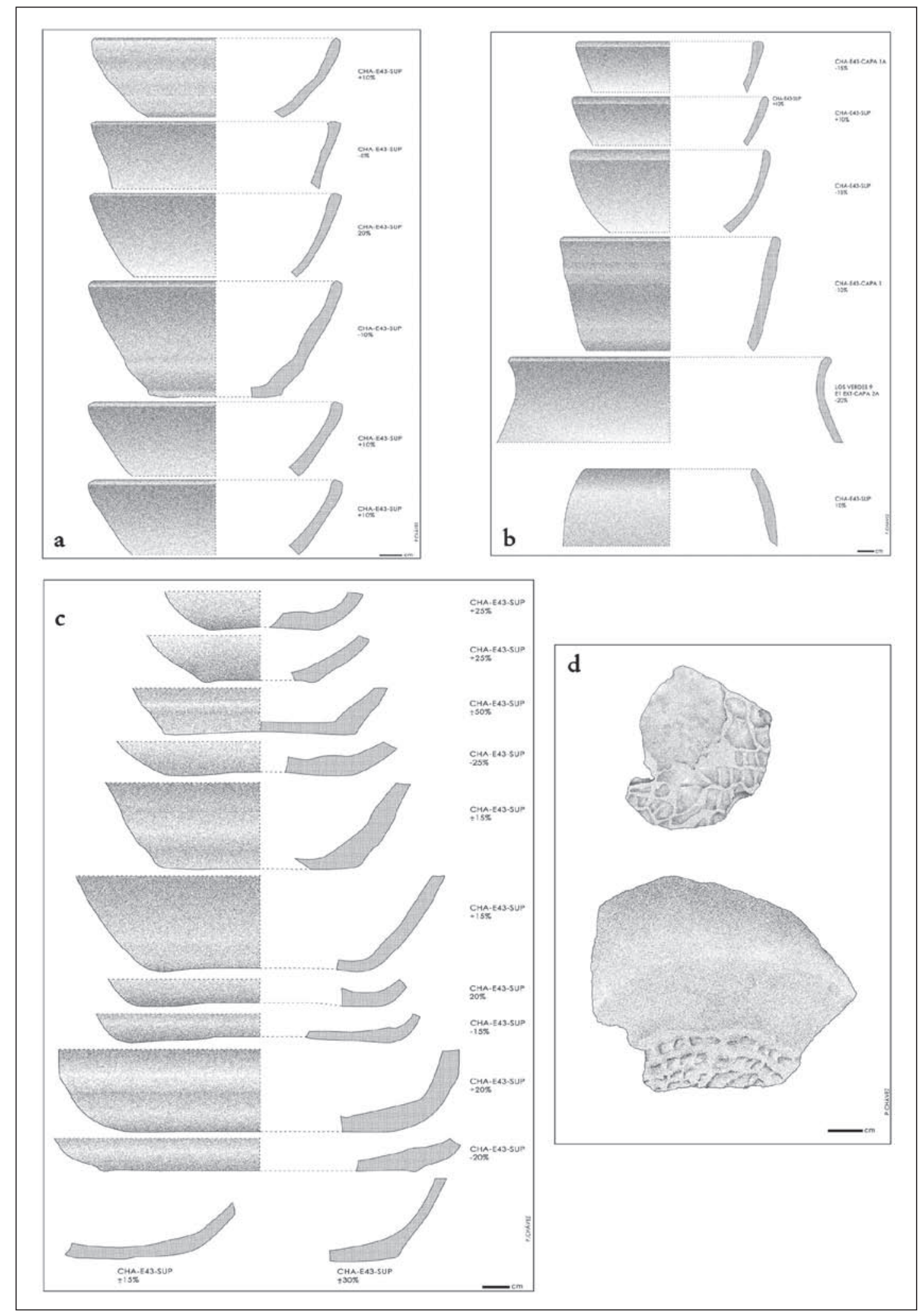

Figura 4. Tipo cerámico Quillagua Tarapacá Café Amarillento (QTC), reconstrucción de formas a partir de fragmentos de la costa: a-b) bordes; c) bases; $\mathbf{d}$ ) bases con improntas de cestería. 
hiperboloide o troncocónico que, a veces, pueden llevar asas mamelonares en el cuello. Esto es idéntico a lo observado en Caserones 1 por True (1980) y Mavrakis (1985), si bien sus tonalidades varían de rojo a negro, distinguiéndose un grupo propio de escudillas, vasos o tazones, que adscribimos al tipo Caserones Negro Pulido o CNP de estos autores.

Según estos análisis, al igual que en Arica, pero sin ser la misma cerámica Faldas del Morro como opinaba Núñez (1969) ${ }^{4}$, la alfarería café de Quillagua Tarapacá estaría ligada a un ceremonialismo que, por lo tosco de su producción, es evidente que no necesitó ser conseguida por intercambio, sino que fue producida localmente. Lo mismo podríamos decir de la cerámica pulida, coincidente con lo planteado por Kautz y colaboradores (1980). Así se define, por lo tanto, una tecnología que denominamos "expeditiva" y de gran escala, donde la manufactura de la cerámica se realizaría durante el tiempo mismo del ceremonial, por lo que muchas veces ni siquiera fue cocida. Sin duda, dicha tecnología era conocida por la población al igual que en el resto de los Valles Occidentales, aunque falta dilucidar este hecho en contextos más tempranos y domésticos, ya que por el momento contamos con muy pocas muestras, entre las que se cuenta la de Cáñamo con su tipo Alisado imperfecto (Núñez y Moragas 1983).

En cualquier caso, la presencia mayoritaria del tipo Quillagua Tarapacá en Tarapacá 40 y Caserones 1 (Uribe y Ayala 2004; Uribe et al. 2007) sugiere que esta alfarería tiene un origen local y un carácter tanto doméstico como ceremonial, cuyo desarrollo se remontaría a momentos tardíos del Formativo, de acuerdo a los fechados por termoluminiscencia de 660 y 665 DC que hemos obtenido para ella en Quillagua (Agüero et al. 2001, 2006). Sin embargo,

\footnotetext{
4 Se debe precisar que en la costa de Iquique aún no se registra cerámica con antiplástico orgánico en su pasta (concha y/o vegetales molidos), aspecto que define a la alfarería Faldas del Morro y Azapa de los Valles Occidentales de Arica, y que caracteriza al Formativo Temprano costero desde el extremo sur de Perú hasta la desembocadura del río Camarones (Santoro 1981, 2000; Muñoz et al. 1991; Schiappacasse et al. 1991; Muñoz 2004, 2005).
}

juzgar por las fechas radiocarbónicas de Tarapacá 40A, pudo haberse iniciado un poco antes como también lo sugieren las dataciones por termoluminiscencia de 200 y 290 DC para cerámica semejante en Quillagua y, recientemente, en Pisagua (Gallardo et al. 1991; Méndez-Quirós y Uribe 2006). Asimismo, pudo continuar en uso hasta 970 DC, de acuerdo a un fechado de Caserones I (Méndez-Quirós y Uribe 2006), y a muestras superficiales de Quillagua (preliminares y no publicadas) que ubican a este tipo entre $1045 \mathrm{y}$ 1095 DC, colindando con los inicios del Intermedio Tardío (Agüero et al. 1999). Complementariamente, el tipo QRP cuenta con un fechado por termoluminiscencia de 895 DC en Caserones (Méndez-Quirós y Uribe 2006), confirmando que se trata de expresiones cerámicas contemporáneas y que ambas caracterizan la alfarería del Formativo Tardío.

\section{Comportamiento de la cerámica formativa en la costa de Tarapacá}

Conforme a los antecedentes, análisis de laboratorio y trabajos de campo, clasificamos el material y evaluamos la tipología expuesta a partir de la cerámica de seis asentamientos excavados en la costa de Tarapacá, ubicados al sur de Iquique y en la desembocadura del río Loa (Figura 5). De norte a sur, los sitios son: Los Verdes 9, Sarmenia, Pabellón de Pica, Chomache 1, Punta Blanca y Caleta Huelén Alto, que representan los sectores septentrional (Los Verdes 9 y Sarmenia), central (Pabellón de Pica, Chomache 1 y Punta Blanca) y meridional (Caleta Huelén Alto) de la costa de Iquique, cuyos asentamientos remiten a un patrón arquitectónico bastante permanente aunque disperso, y característico de este litoral (Adán y Urbina 2004 Ms; Figura 6).

El material recuperado sistemáticamente mediante un muestreo dirigido de acuerdo a la diversidad arquitectónica de los asentamientos consistió en 419 fragmentos, tanto de superficie $(n=325)$ como de excavación $(n=93)$. Caleta Huelén Alto y Pabellón de Pica reúnen la mayor cantidad, correspondiente al $46.06 \%$ y $30.31 \%$ de la muestra, y proviene de dos estructuras dispersas y otra única, respectivamente. 


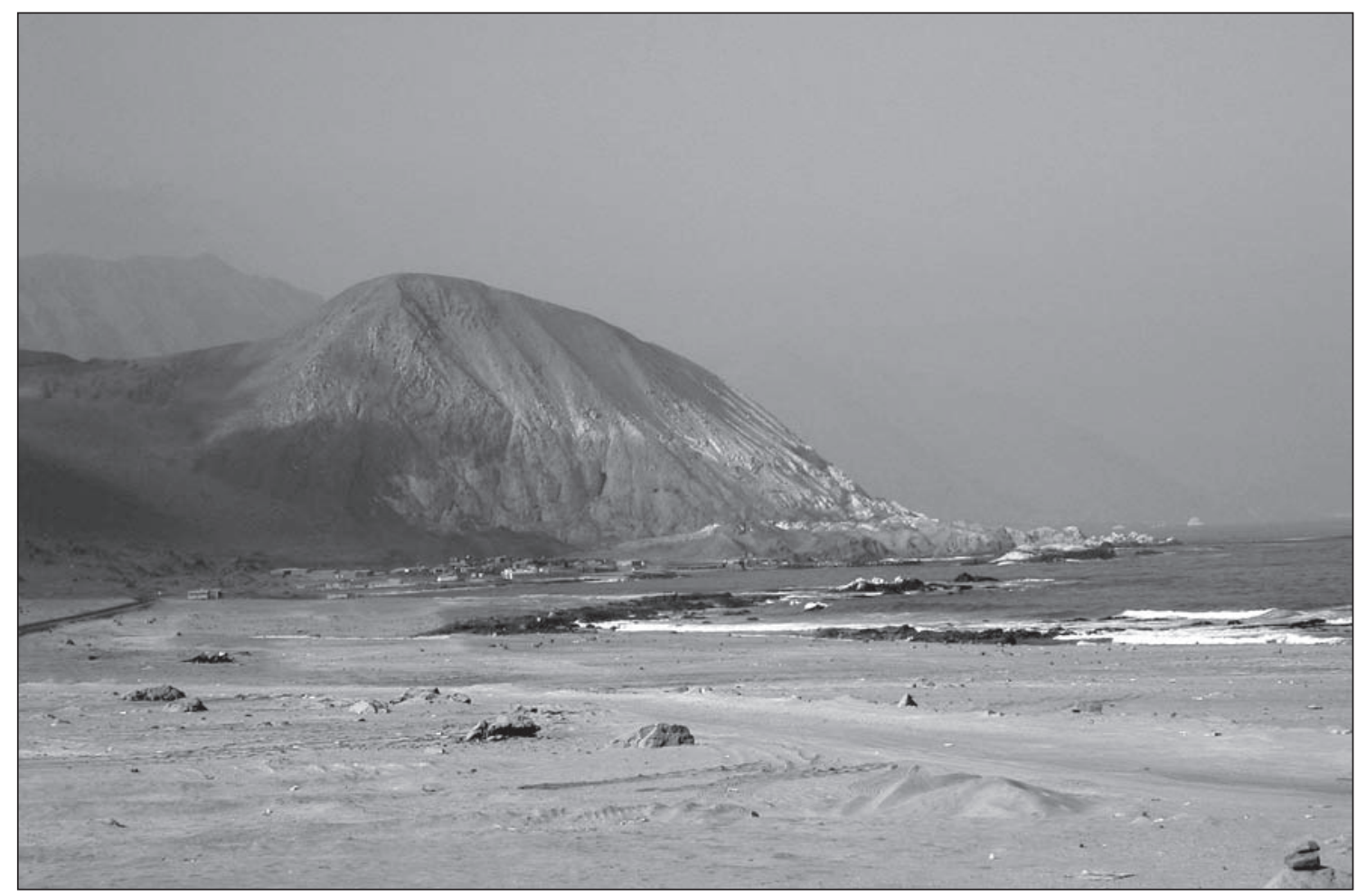

Figura 5. Paisaje árido de la plataforma costera al sur de Iquique, localidad de Pabellón de Pica.

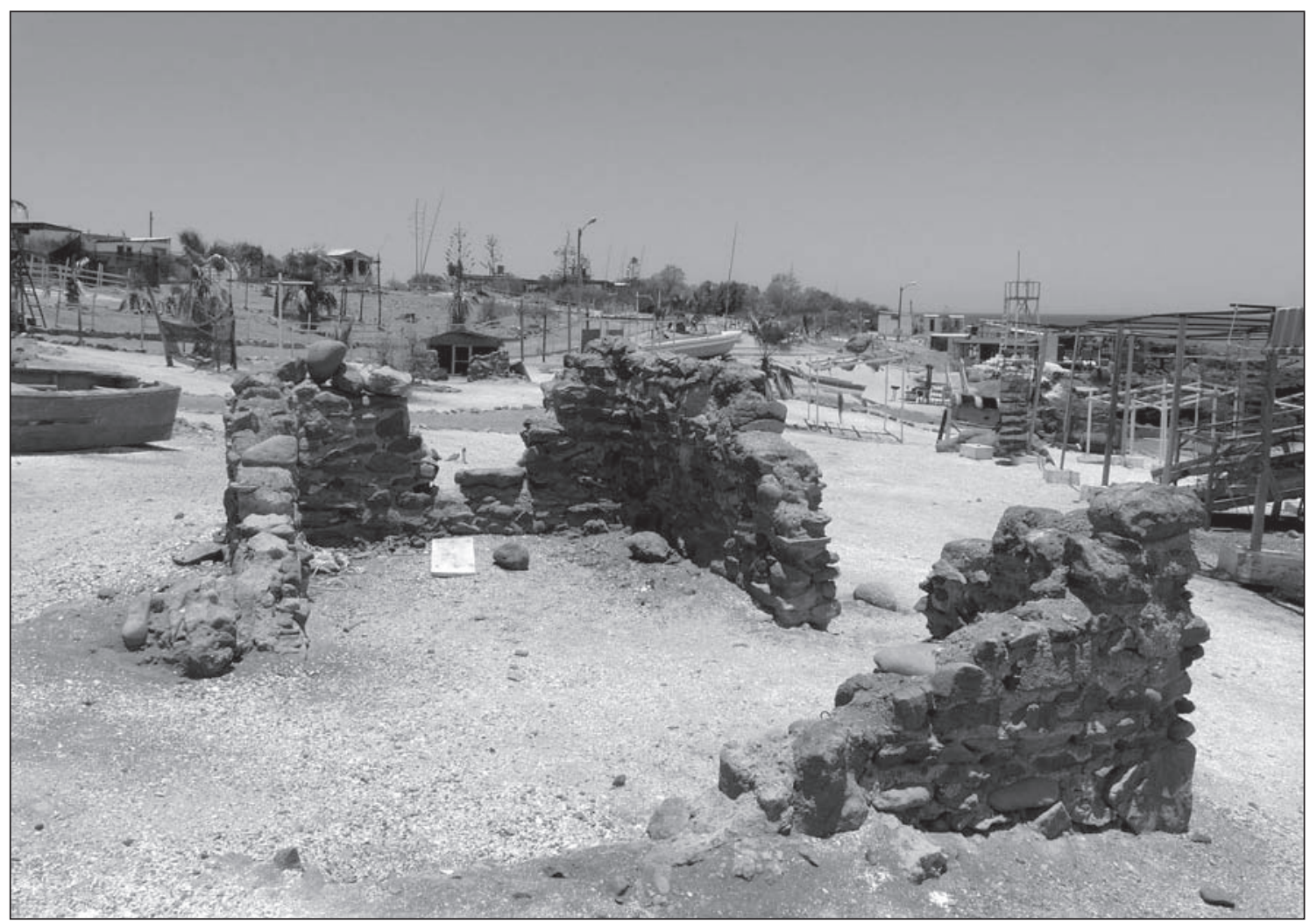

Figura 6. Arquitectura de la costa sur de Iquique, localidad de Sarmenia. 
Por su parte, Los Verdes 9 y Chomache 1 sólo abarcan el $9.55 \%$ de los fragmentos en cada caso, los que también pertenecen a uno y dos recintos, respectivamente. Por último, Sarmenia y Punta Blanca aportan $2.86 \%$ y $1.67 \%$ de los materiales, obtenidos en una y dos estructuras con cerámica, respectivamente. Asimismo, con fines comparativos, incluimos una muestra de los sitios Pisagua B y N con cinco y 25 estructuras, donde se recuperaron 406 fragmentos de superficie y excavaciones, 330 y 76 provenientes de tres y siete recintos, respectivamente (Uribe et al. 2007).

Para el análisis estadístico se consideraron tanto los tipos cerámicos individualmente como agrupados de acuerdo a su procedencia, adscripción cultural, temporalidad y características depositacionales.

En la muestra analizada se determinaron 13 clases cerámicas correspondientes a tipos cerámicos seguros y algunos dudosos, junto con dos categorías residuales referidas a Arcilla (ARC) y Erosionados (ERO). En primer lugar, se registró la posible presencia del tipo Loa Café Alisado (LCA) y, con mayor seguridad, de los tipos Quillagua Tarapacá Café Amarillento (QTC), Quillagua Rojo Pulido (QRP) y Caserones Negro Pulido (CNP). Estos los agrupamos dentro de un componente temprano (ca.900 AC-800 DC) acotado principalmente al Formativo Tardío (200800 DC), donde también se podría incluir cerámica monocroma Loa Rojo Alisado (LRA) y ocasionales ejemplares San Pedro Negro Pulido (SNP), ambos del Salar de Atacama.

Luego aparece una gran variedad de expresiones tanto de la costa como del interior que configuran los componentes Pica-Tarapacá y Loa-San Pedro, constituidos por tipos no decorados pertenecientes al período Intermedio Tardío de Tarapacá y Atacama (ca. 9001450 DC). Dentro del primero, identificamos los tipos Pica Charcollo (PCH), Pica Gris Alisado (PGA) y Pica Chiza (PCZ), mientras que en el segundo distinguimos los tipos Aiquina (AIQ), Dupont (DUP) y Turi en distintas versiones (TRA y TGA), a los que se suman algunas evidencias no decoradas de Arica en los Valles Occidentales (Uribe 1999, 2002; Uribe et al. 2007). La ausencia de cerámica decorada, especialmente pintada y proveniente del altiplano y de Arica, sugiere que se trata de un momento inicial del Intermedio Tardío, conocido como fase Tarapacá (900-1200 DC) en la región (Uribe et al. 2007).

En consecuencia, el material se reparte entre los componentes cerámicos Formativo y Pica-Tarapacá, siendo ambos bastante equivalentes en frecuencias y predominantes (Figura 7), ya que representan el 29.83\% y $31.03 \%$ de la muestra, respectivamente, seguido por los componentes Loa-San Pedro y Arica (3.34\% y $0.48 \%$ ). Esto sugiere que las ocupaciones costeras pudieron iniciarse en el Formativo Temprano, pero alcanzaron su máximo desarrollo en pleno Formativo Tardío (200-80o DC), continuando hasta comienzos del Intermedio Tardío y sin percibirse ocupaciones posteriores a $1200 \mathrm{DC}$. Lo anterior coincide con lo observado en la región para los inicios del Intermedio Tardío, pues:

"El análisis de agrupamiento de acuerdo a las frecuencias relativas de su cerámica, muestra que si bien todos los sitios habitacionales estudiados fueron ocupados a lo largo del período Intermedio Tardío, éstos se separan claramente en dos subgrupos. Por un lado, los dos sitios de la costa y, por el otro, los del interior (valles bajos y quebradas altas). Los sitios de la costa se diferencian de los del interior por la dominancia de los tipos locales PCH, PGA y PCZ (67 a $80 \%$ ), característicos del componente Pica Tarapacá del Intermedio Tardío, y la casi total ausencia de los tipos Altiplano Tarapacá. No obstante, destaca la recurrencia de materiales de Arica, Atacama y un conjunto de fragmentos indeterminados" (Uribe et al. 2007: 157).

Sin embargo, lo más importante es que esta situación remite a lo observado en la quebrada de Tarapacá:

"La dinámica de ocupación, movilidad e interacción de vasijas y poblaciones queda más clara al evaluar cuantitativamente la muestra clasificada de acuerdo a los conjuntos o componentes cerámicos determinados en esta prospección. De este modo, el componente Formativo Temprano así como los componentes del período Medio e Histórico apenas comprenden bajo el $1 \%$ del total; en cambio, aquellos del Formativo Tardío y del 


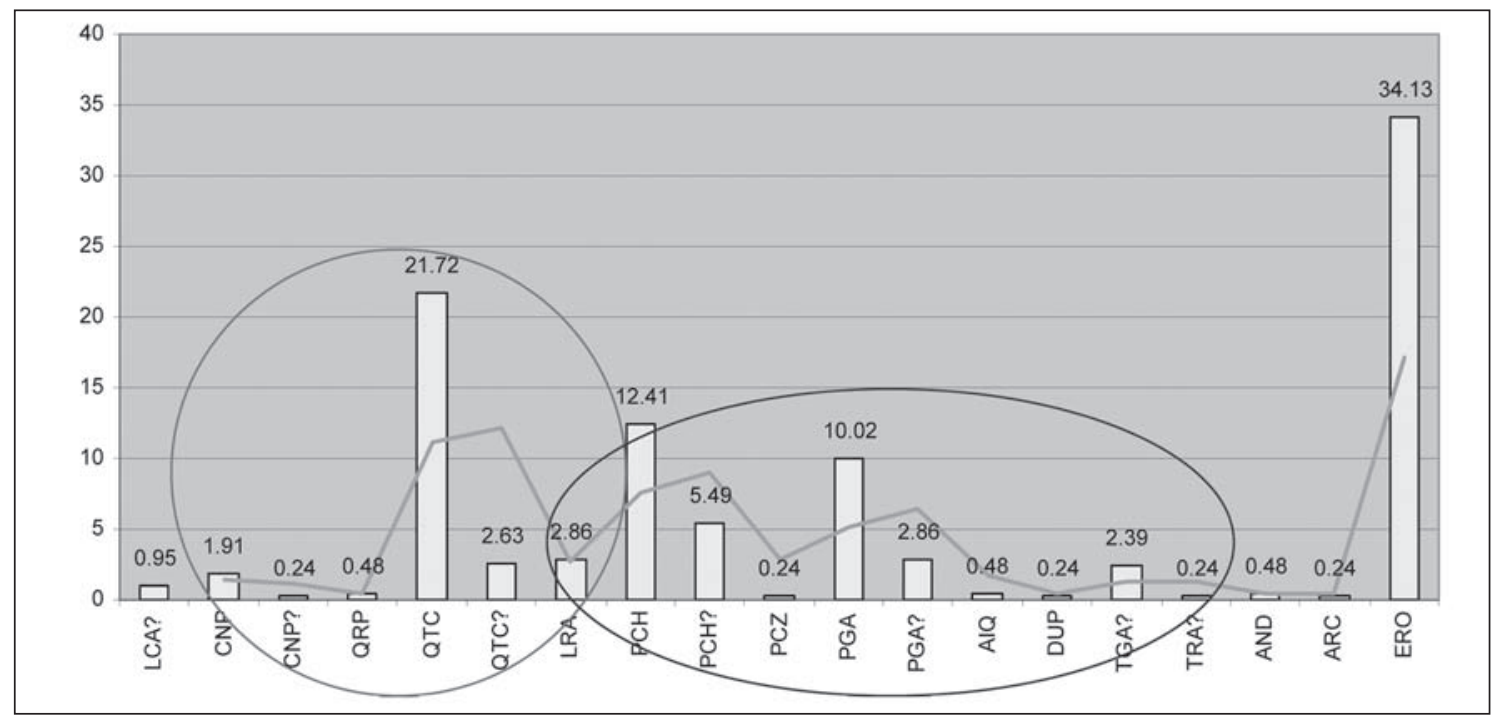

a

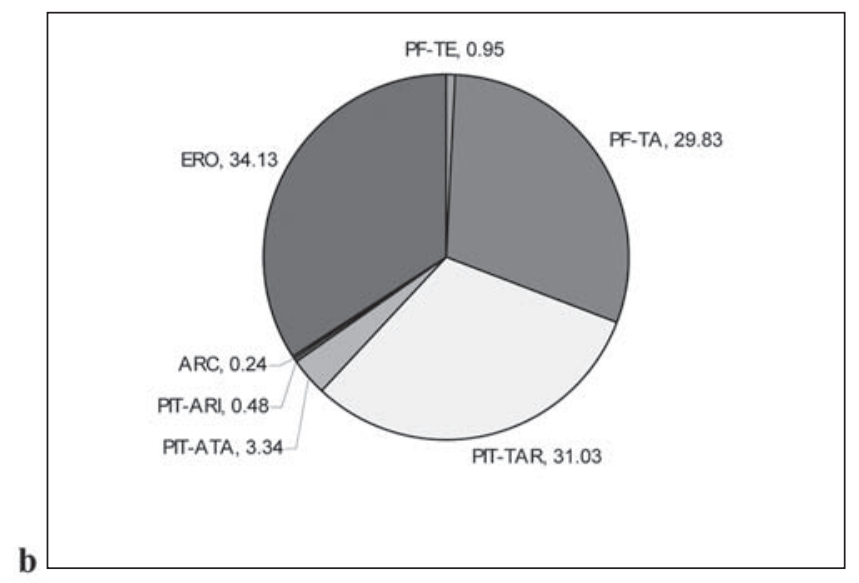

Figura 7. a) Distribución general de las frecuencias relativas de los tipos cerámicos de la costa sur de Iquique; b) Representación porcentual de los componentes cerámicos identificados (PF-TE, Formativo Temprano; PF-TA, Formativo Tardío; PIT-TAR, Intermedio Tardío Tarapacá; PIT-ATA, Intermedio Tardío Atacama; PIT-ARI, Intermedio Tardío Arica; ARC, Arcilla; ERO, Erosionado).

Intermedio Tardio en su conjunto representan cerca del $30 \%$ y más del 50\%, respectivamente. Por su parte, el componente Tardío o Inca se acerca al $4 \%$ de representación. Lo anterior da cuenta de dos momentos significativos de la ocupación del curso bajo de la quebrada, uno en el Formativo Tardío y otro durante el Intermedio Tardío. Observando la curva de tendencia de los promedios de frecuencia cerámica, esto indica que dicha ocupación comenzó en los inicios del Formativo, pero intensificándose bruscamente en el Formativo Tardio, alcanzando su clímax en el Intermedio Tardío y declinando violentamente en el mismo periodo (ca. 1200 DC). Finalmente, mantiene una baja intensidad hasta épocas recientes" (Uribe $2008 \mathrm{Ms})$.
Entonces, el comportamiento cerámico general de los sitios de la costa de Iquique demostraría un particular desarrollo local, estrechamente ligado a los valles y oasis interiores, pudiendo corresponder a diversas poblaciones que comparten una misma cultura (al menos su alfarería), en clara interacción con las principales regiones culturales del norte de Chile, especialmente con Atacama y Arica, a lo largo de un extenso Formativo Tardío que se extendería hasta inicios del Intermedio Tardío. En este mismo lapso, todavía no hemos observado otras expresiones cerámicas tempranas pertenecientes a las entidades altiplánicas Wankarani, Chiripa o Pukara (Ayala y

\footnotetext{
$\mathrm{N}^{\circ} 37 / 2009$

Estudios AtACAMEÑos

Arqueología y Antropología Surandinas
} 


\begin{tabular}{|c|c|c|c|c|c|c|c|}
\hline Cerámica & Los Verdes 9 & Sarmenia & $\begin{array}{c}\text { Pabellón de } \\
\text { Pica }\end{array}$ & Chomache 1 & Pta. Blanca & $\begin{array}{c}\text { Caleta Huelén } \\
\text { Alto }\end{array}$ & Total \\
\hline LCA? & & & 4 & & & & 4 \\
\hline CNP & 1 & & 7 & & & & 8 \\
\hline CNP? & & & & 1 & & & 1 \\
\hline QRP & & 2 & & & & & 2 \\
\hline QTC & 5 & & & 4 & 3 & 79 & 91 \\
\hline QTC? & & 1 & & & 1 & 9 & 11 \\
\hline LRA & & & & 10 & 2 & & 12 \\
\hline $\mathrm{PCH}$ & 1 & & 50 & 1 & & & 52 \\
\hline $\mathrm{PCH}$ ? & & 3 & 16 & 4 & & & 23 \\
\hline PCZ & & & 1 & & & & 1 \\
\hline PGA & 19 & & 23 & & & & 42 \\
\hline PGA? & 11 & & & 1 & & & 12 \\
\hline AIQ & & & & 2 & & & 2 \\
\hline DUP & & & & & 1 & & 1 \\
\hline TGA? & & & 3 & 7 & & & 10 \\
\hline TRA? & & & 1 & & & & 1 \\
\hline AND & & & & 2 & & & 2 \\
\hline ARC & & & & 1 & & & 1 \\
\hline ERO & 3 & 6 & 22 & 7 & & 105 & 143 \\
\hline Total & 40 & 12 & 127 & 40 & 7 & 193 & 419 \\
\hline$\%$ & 9.55 & 2.86 & 30.31 & 9.55 & 1.67 & 46.06 & 100 \\
\hline
\end{tabular}

Tabla 1. Distribución espacial de los tipos cerámicos por sitio estudiado y según sus frecuencias absolutas.

\begin{tabular}{|c|c|c|c|c|c|c|c|c|c|c|c|c|c|c|c|c|c|c|c|c|c|c|c|}
\hline Cerámica & 1 & 1 Amp. Muro N & $\mathbf{I A}$ & ${ }_{1 B}$ & $\begin{array}{l}\mathrm{IB} / \\
\mathrm{ID}\end{array}$ & 2 & $2 \mathrm{~A}$ & 3 & $3 \mathrm{~A}$ & 3B & 4 & $4 \mathrm{~A}$ & $4 B$ & $4 \mathrm{C}$ & $4 \mathrm{D}$ & $4 / 5$ & $5 \mathrm{~A}$ & $6 \mathrm{~A}$ & $6 \mathrm{~B}$ & $6 \mathrm{C}$ & $7 \mathrm{~A}$ & $8 \mathrm{~A}$ & Total \\
\hline LCA? & & & & & & & & & & & & & & 1 & & & & & & & 1 & & 2 \\
\hline $\mathrm{CNP}$ & & & & & & & 1 & & & & & & & & 1 & & & & & & & 1 & 3 \\
\hline QTC & & & 10 & & & & 3 & & 2 & & 1 & & & & & 1 & & 1 & & 1 & & & 19 \\
\hline QTC? & & 2 & & 1 & & & & & & & & & & & & & & & & & & & 3 \\
\hline LRA & & & & & & & & & & & & & & & & 1 & & & & & & & 1 \\
\hline $\mathrm{PCH}$ & & & & & & & & & 1 & & & & & & 1 & & 1 & & & & & 2 & 5 \\
\hline $\mathrm{PCH}$ ? & 1 & & & & & & & 2 & & & & & & & & & & & 1 & & & & 4 \\
\hline $\mathrm{PCZ}$ & & & & & & & & & & & & & & 1 & & & & & & & & & 1 \\
\hline PGA & & & 1 & & & & 6 & & 4 & 1 & & 2 & & 1 & & & 2 & 3 & & & & & 20 \\
\hline PGA? & & & 1 & 1 & & & 6 & & 1 & 2 & & 1 & & & & & & & & & & & 12 \\
\hline TGA? & & & & & 2 & & & & & & & & & & & & & & & 1 & & & 3 \\
\hline ARC & & & & & & & & & & & & & & & & 1 & & & & & & & 1 \\
\hline ERO & & & 5 & & & 5 & & 1 & & & 1 & & 2 & 1 & 3 & & & 1 & & & & & 19 \\
\hline Total & 1 & 2 & 17 & 2 & 2 & 5 & 16 & 3 & 8 & 3 & 2 & 3 & 2 & 4 & 5 & 3 & 3 & 5 & 1 & 2 & 1 & 3 & 93 \\
\hline
\end{tabular}

Tabla 2. Distribución estratigráfica de los tipos cerámicos según sus frecuencias absolutas y presencia por capas o estratos (Gris claro, capas superficiales; Gris medio, capas intermedias; Gris oscuro, capas inferiores). 
Uribe 2003; Uribe y Ayala 2004; Ayala et al. 2008), y menos aún alguna presencia tiwanaku e inca.

Más particularmente, en casi todos los asentamientos estudiados identificamos ambos componentes, observando una diversidad levemente mayor en la muestra de superficie y que se restringe en el material de excavación a los dos componentes y períodos ya señalados, con un marcado carácter tarapaqueño (Tablas 1 y 2). La excepción la constituye Caleta Huelén Alto donde la cerámica Quillagua Tarapacá predomina. En consecuencia, proponemos una ocupación exclusiva del Formativo Tardío en este lugar. Lo anterior es coincidente con la formación de depósitos principalmente superficiales, que no presentan más de dos estratos. En cambio, en Pabellón de Pica se reconocen posibles expresiones del tipo Loa Café Alisado, con gran probabilidad perteneciente al Formativo Temprano, lo que permite sugerir que aquí ocurrió la ocupación más temprana detectada hasta ahora en estos sitios. ${ }^{5} \mathrm{Si}$ bien aparecen otros tipos más tardíos, tal situación es estratigráficamente consistente ya que los ejemplares Loa Café Alisado se ubican en los estratos intermedios y finales. Al respecto, también destacamos la presencia del tipo Caserones Negro Pulido en esos estratos, lo que podría indicar una ocupación de finales del Formativo Temprano e inicios del Formativo Tardío. Sin embargo, el asentamiento adquiere una mayor intensidad ocupacional hacia el Intermedio Tardío, ya que la mayoría de su material se adscribe a los componentes Pica-Tarapacá y Loa-San Pedro.

Por su parte, Los Verdes 9 y Chomache 1, aun cuando replican esta ocupación de inicios del desarrollo regional con conexiones hasta Arica en el caso del segundo también sugieren una situación previa representada por la cerámica Quillagua Tarapacá y del tipo Caserones Negro Pulido. Del mismo modo que en Pabellón de Pica, se trata de depósitos de considerable profundidad y diversidad estratigráfica, donde se mezcla la

\footnotetext{
5 Lo mismo ocurriría en otros sectores de la costa de Iquique, ya que la identificación de bordes en coma ha confirmado la presencia del tipo Loa Café Alisado en Chomache y Punta Blanca, si bien no en los sitios que analizamos en este artículo.
}

cerámica formativa y del Intermedio Tardío desde la superficie hasta el inicio de la ocupación, pero con una concentración mayor de esta última en los estratos intermedios y disminuyendo en los más profundos. Por consiguiente, más por densidad y frecuencia que por presencia o ausencia absoluta de ambas cerámicas, es posible en estos casos segregar una ocupación del Formativo Tardío de otra del Intermedio Tardío. Todo lo anterior lleva a suponer que no existe un recambio poblacional, sino que se trata del flujo natural en el que se han desenvuel to las ocupaciones con cerámica, aunque distinguiéndose una intensificación de la ocupación hacia inicios del desarrollo regional. De acuerdo a ello, los sitios Sarmenia y Punta Blanca representarían justamente esta situación propia del Formativo Tardío y con escuetas evidencias del desarrrollo regional tardío, aunque a su vez también diferente a Caleta Huelén Alto. El material cerámico en ellos es muy escaso y se encuentra en depósitos tanto livianos como densos, y casi siempre en los estratos más superficiales. En este sentido, resulta coherente que las evidencias formativas tardías de estos dos sitios sean tan acotadas, ya que lo mismo ocurre en Caleta Huelén Alto, aludiendo a patrones de asentamiento que sufren cambios en el tiempo. En cualquier caso, es posible hipotetizar que dentro de una ocupación continua del litoral a partir del establecimiento de comunidades con alfarería a fines del Formativo Temprano y dando paso al Formativo Tardío, se mantuvieron ocupaciones más bien pasajeras y livianas, seguramente de alta movilidad y/o estacionales, que dejaron evidencias de eventos únicos y depositación más bien horizontal, de manera distinta a lo que ocurriría posteriormente.

\section{Consideraciones preliminares sobre cerámica, función y asentamiento}

Lo que hemos expuesto sugiere la existencia durante el Formativo Tardío de un proceso de exploración y explotación creciente del borde costero por parte de las comunidades bajo un sistema fragmentado, seguramente con núcleos en zonas de desembocadura donde convergerían estacionalmente y con múltiples fines a partir de los cuales se dispersarían por el litoral e incluso hacia el interior en diversos momentos. De 


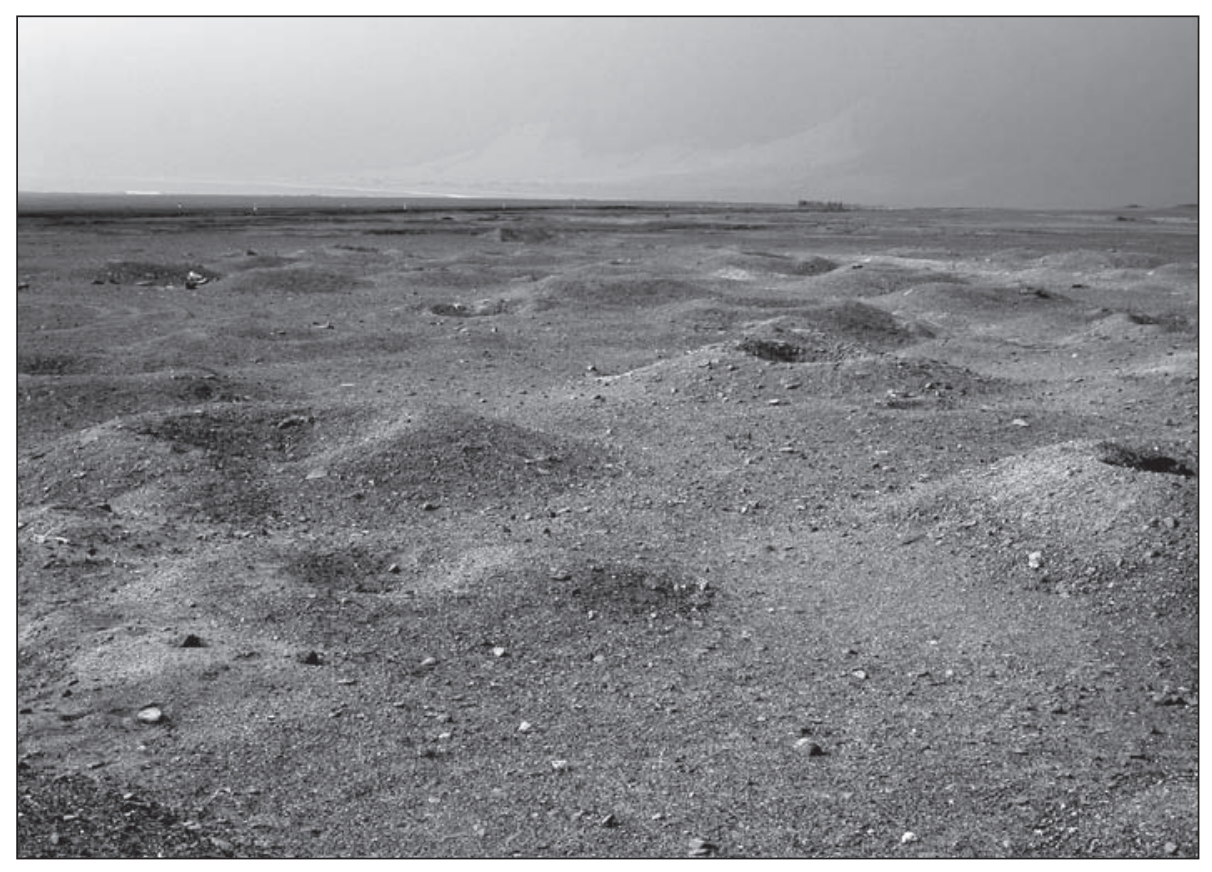

Figura 8. Cementerio de túmulos y fosas en la costa sur de Iquique, localidad de Chipana.

acuerdo a ello, no es extraño encontrar en torno a la desembocadura del Loa, desde Chipana y al sur de Caleta Huelén una notable concentración de cementerios de túmulos y fosas que remiten justamente a esta época (Núñez 1971; Moragas 1995; Agüero y Uribe 2008 Ms; Figura 8). En este sentido, las poblaciones se mantendrían en una constante y alta movilidad desde inicios hasta finales del Formativo, seguramente bajo el mismo patrón arcaico y elocuente en la baja densidad de sus depósitos, pero abarcando un territorio cada vez mayor por parte de aquellas que acceden a y/o producen alfarería. Bajo este supuesto, hacia el Intermedio Tardío ese mismo patrón sufriría una fuerte transformación, volviéndose más estable como se deduce de los densos depósitos excavados en Los Verdes 9, Pabellón de Pica y Chomache 1, aunque a la vez restringiéndose cada vez más a ciertos puntos en plena costa arreica y sin tanta dependencia de la desembocadura del Loa.

Profundizando en el patrón de asentamiento analizamos y exponemos las características depositacionales y el comportamiento del material cerámico. En general, se detectó una depositación de carácter residencial en todos los sitios, con fragmentos de dimensiones que apenas superan los $5 \mathrm{~cm}$ de largo promedio y un espesor menor a $1 \mathrm{~cm}$, aunque con una considerable variación dependiendo de la densidad de los depósitos (DS tamaño $2.56 \mathrm{~cm}$ ), lo que también incide en una alta restaurabilidad que alcanza $11.22 \%,{ }^{6}$ un importante número de indicadores de forma correspondientes a $23.63 \%$, y marcadas huellas de uso en proporciones semejantes de $21.24 \%$, sobre todo hollín. Todo indica que se trata de desechos primarios, secundarios y abandonados de facto, ya sea por tratarse de pisos domésticos, basureros o por abandono repentino de los sitios. Tal situación es generalizada tanto para las ocupaciones formativas como para aquellas de inicios del desarrollo regional. Sin embargo, los escuetos desechos formativos sugieren que los contextos por abandono del asentamiento son propios de esta época, a diferencia de lo que ocurre en los depósitos

\footnotetext{
6 Se presentan los porcentajes obtenidos respecto del total de la muestra, porque dichos valores aumentan extremadamente si se evalúan de acuerdo sólo a la cantidad de los fragmentos que presenta cada variable. Por lo pequeño de la muestra, este ejercicio daría una imagen sobredimensionada de tales indicadores.
} 
más tardíos donde la situación es más heterogénea y con mayor densidad cerámica, señalando una mayor estabilidad y permanencia en los asentamientos, dando incluso origen a la formación de basurales. Lo anterior es coincidente con que la restauración es más propia de la cerámica Quillagua Tarapacá que de la de Pica-Tarapacá, y que las evidencias de cocina y hollín son más propias de esta última alfarería, de manera coherente con la recurrencia de ollas del tipo Pica Gris Alisado. Al contrario, para las evidencias formativas estas características son mucho menos notorias, a la vez que los tiestos para cocinar son bastante menos, de acuerdo al predominio de escudillas, tazones y cuencos pequeños.

Centrándonos en la cerámica del Formativo, especialmente Tardío, destacan las formas no restringidas del tipo Quillagua Tarapacá (al menos el 48\% de los indicadores de forma reconstruidos), salvo por algunas restringidas simples que tienen el borde levemente invertido; todas con bases convexas a planas y anulares. Sus diámetros de boca van de los 8 a $12 \mathrm{~cm}$, mientras que las bases varían de 4 a $11 \mathrm{~cm}$. Las mismas se complementarían con piezas pulidas similares de los tipos Quillagua y Caserones, además de algunos ejemplares Loa Rojo Alisado, principalmente restringidos, al igual que otros mínimos Quillagua Tarapacá. Se trata, por lo tanto, de piezas esencialmente pequeñas, fáciles de elaborar y llevar, es decir, contenedores menores, de uso doméstico pero no de cocina, sin gran capacidad para contener líquidos tanto por su tamaño como por su mínima calidad para ello. Esto sugiere su empleo como potes para transportar, servir y/o presentar, con una finalidad más adecuada para el encuentro y la sociabilidad que con un fin culinario práctico. Lo anterior es aún especulativo, pero resulta coherente con su escasa presencia habitacional y recurrente aparición en contextos funerarios o, como en este caso, en lugares de gran aglutinación, como Caleta Huelén Alto, en cuyos alrededores también se concentran manifestaciones funerarias (Núñez 1971; Moragas 1995; Agüero y Uribe $2008 \mathrm{Ms}$ ). Este panorama es cualitativamente idéntico al del interior, al menos en sitios habitacionales y cementerios como Caserones, Tarapacá 40 y Quillagua (Agüero et al. 2001, 2006;
Uribe et al. 2007), permitiéndonos proponer una funcionalidad ceremonial para esta alfarería, tanto o más importante que la doméstica.

De esta manera, considerando sólo la cerámica, los patrones de ocupación y asentamiento se estarían estructurando con una marcada intencionalidad ritual que pudo guiar y a la vez ser producto de las relaciones sociales que se fueron desarrollando a través del Formativo Tardío, tanto en la exploración así como en la explotación de los diversos espacios, especialmente de la costa, en la medida que se popularizan las comunidades que acceden, usan y/o producen cerámica. Una situación así es coincidente con varios estudios centrados en el problema del surgimiento de la alfarería, que señalan que el escenario privilegiado para su aparición estuvo en las sociedades móviles y, dentro de ellas, en aquellas donde se dieron situaciones de competitividad socioeconómica derivada de los modos de explotación de los recursos, ocupación del espacio y concepciones de mundo, con énfasis en la recolección y la integración de nuevos roles sociales, no sólo masculinos (Barnett y Hoopes 1995; Uribe 2004, 2006a).

\section{* Recapitulación y conclusiones}

En conformidad con el análisis tipológico, cronológico y funcional desarrollado con la muestra cerámica y los sitios estudiados del litoral de Iquique, hemos podido establecer un marco temporal más amplio para el período Formativo de Tarapacá y su costa. Sobre esta base, por lo tanto, podemos pasar a otro nivel de reflexión que nos permite contribuir con algunos alcances al proceso de complejidad que estarían experimentando las poblaciones durante esta etapa clave de la prehistoria de la región. Desde esta perspectiva, ahondaremos en las apreciaciones que hemos esbozado a partir de ciertas inferencias sobre la evolución de la ocupación y del asentamiento en el litoral. No obstante, es obvio que para validar nuestras interpretaciones es necesario realizar estudios más finos de composición y procedencia de la alfarería estudiada, incluir la información contextual de los 
sitios y depósitos trabajados, así como conseguir más dataciones absolutas. Por lo mismo, nuestras conclusiones deben considerarse preliminares e hipotéticas.

Actualmente reconocemos dos expresiones cerámicas para el Formativo de Tarapacá, sin vinculaciones con el altiplano, destacando una alfarería inicial y otra más tardía (Ayala 2001; Ayala y Uribe 2003; Uribe y Ayala 2004). Una industria inicial de vasijas con bordes en coma que denominamos tipo Loa Café Alisado, la cual se confirma como la más temprana con fechas de termoluminiscencia que van desde $810 \mathrm{AC}$ a 270 DC. La segunda es una industria compuesta por tipos alisados y pulidos Quillagua Tarapacá (QTC y QRP), los cuales muestran una continuidad hasta momentos más tardíos (Ayala 2001; Ayala y Uribe 2003; Uribe y Ayala 2004). Debido a la mayoritaria presencia de esta cerámica en Tarapacá 40 y Caserones 1, se propone un origen local y un carácter tanto doméstico como ceremonial, cuyo desarrollo se remontaría a momentos tardíos del Formativo, desde 200 DC hasta finales del primer milenio de nuestra Era, articulándose con los inicios del desarrollo regional alrededor de 800900 DC (Méndez-Quirós y Uribe 2006; Uribe et al. 2007). Ambas industrias, que ahora confirmamos como parte de una misma tradición alfarera temprana de Tarapacá -alisada y monocroma-, abarcarían esencialmente sus tierras bajas, permitiéndonos postular que las poblaciones de los valles y oasis aledaños a la Pampa del Tamarugal se articularían con aquellas de la costa, logrando una integración durante el Formativo Tardío a través de la cerámica Quillagua Tarapacá. No obstante, tampoco se puede desconocer una relación e interacción con las poblaciones de Atacama a través del río Loa (p.e., tipo Loa Rojo Alisado) y, en menor medida, con los Valles Occidentales de Arica a través de la quebrada de Tiliviche y Tana y Camarones (Muñoz et al.1991; Aufderheide et al. 1994). En este marco, las vinculaciones con el altiplano, ya sea por ausencia de investigaciones o de mayores registros formativos en las tierras altas, serían nulas (Ayala 2001; Agüero et al.2006), al menos desde la cerámica si se consideran los análisis petrográficos y químicos de Kautz y colaboradores (1980) y Núñez y Moragas (1983).
Al revisar esta situación en la costa, registramos toda la tradición definida a través de sus distintos tipos y grupos cerámicos desenvolviéndose dentro de una ancestral dinámica local. Destacan los tipos formativos Loa Café Alisado y Quillagua Tarapacá (QTC y QRP) en conjunto con ciertas manifestaciones atacameñas contemporáneas (especialmente el tipo LRA), con los tipos Pica Charcollo, Pica Gris Alisado y Pica Chiza Modelado del componente Pica-Tarapacá, otros del componente Loa-San Pedro (TRA y TGA) y, quizás, de Arica, todos de inicios del Intermedio Tardío. La mayor parte del material se reparte principalmente entre los componentes Formativo y Pica-Tarapacá, siendo ambos bastante equivalentes y dominantes, representando cada uno de ellos casi un tercio de la muestra (29.83\% y $31.03 \%$, respectivamente). Esto permite plantear que las ocupaciones costeras pudieron iniciarse en el Formativo Temprano, pero alcanzaron un gran desarrollo en pleno Formativo Tardío (200-800 DC), continuando hacia los inicios del Intermedio Tardío para perder intensidad después de 1200 DC.

Tal situación es prácticamente idéntica a la detectada en el interior, en la quebrada de Tarapacá (Uribe et al. 2007; Uribe $2008 \mathrm{Ms}$ ), demostrando que ambos espacios y sus poblaciones estarían involucradas a través de la cerámica, de su producción y distribución. Probablemente, estas entidades habrían formado una unidad económica y cultural, con consecuencias sociales y políticas como se deja entrever por el uso doméstico, pero sobre todo ceremonial de las vasijas, articulando fuertemente el territorio entre el curso bajo de dicha quebrada, el Loa a la altura de Quillagua, quizás más al norte hasta Tana-Tiliviche en Camiña ${ }^{7}$ y todo el litoral asociado.

En general, ambos componentes y ocupaciones se identificaron en casi todos los sitios estudiados, tanto en superficie como en excavaciones, apreciándose una diversidad levemente mayor en la primera que se

\footnotetext{
7 Información inédita sobre el rescate de cementerios formativos en esta quebrada, señala la existencia de los mismos componentes cerámicos aquí determinados (Carrasco com. pers. 2006).
} 
restringe en las excavaciones. Destaca Caleta Huelén Alto, donde la cerámica Quillagua Tarapacá es predominante, por lo que se trataría de una ocupación exclusiva del Formativo Tardío, coincidente con una formación de depósitos principalmente superficiales y de amplia distribución horizontal. Asimismo, los sitios Sarmenia y Punta Blanca representarían esta situación propia del Formativo Tardío, aunque también con escuetas evidencias del desarrrollo regional tardío, pero mostrando ciertas diferencias con Caleta Huelén Alto. El material cerámico en ellos es escaso y se encuentra en depósitos tanto densos como livianos y casi siempre en los estratos más superficiales, mientras que en Pabellón de Pica se reconocieron posibles ejemplares Loa Café Alisado en los estratos intermedios y terminales que alcanzan una considerable profundidad, junto al tipo Caserones Negro Pulido, por lo que planteamos una ocupación de fines del Formativo Temprano e inicios del Formativo Tardío que se desarrolla fuertemente a comienzos del Intermedio Tardío. Siguiendo un patrón semejante, de gran profundidad y diversidad estratigráfica, se encuentran Los Verdes 9 y Chomache 1, pero con ocupaciones principalmente del Formativo Tardío interdigitadas con aquellas de inicios del Intermedio Tardío, donde la presencia tardía disminuye de manera notoria en los niveles terminales mientras el material formativo se mantiene constante.

Lo anterior nos lleva a suponer que no hubo un recambio poblacional sino que se trata del flujo natural en el que se han desenvuelto las ocupaciones con cerámica, aunque distinguiéndose una clara intensificación de los asentamientos hacia inicios del desarrollo regional luego de un constante pero paulatino acercamiento a la costa. En este sentido, resulta coherente que las evidencias formativas tardías sean tan acotadas $y$, a la vez, ampliamente distribuidas, aludiendo a patrones de asentamiento que sufren cambios en su distribución horizontal en el tiempo y en el espacio. Los asentamientos estudiados evidencian durante el Formativo Tardío ocupaciones pasajeras o estacionales, seguramente debido a una alta movilidad, por lo que sus evidencias serían eventos únicos y de gran cobertura costa-interior, de manera distinta a lo que ocurriría después.

Frente a este panorama, recordamos lo sintetizado previamente por Moragas para la zona, y que da cuenta de la concepción de una época de la arqueología del Norte Grande de Chile:

"Hacia el primer milenio $A C$, las poblaciones locales de tradición marítima reciben ciertas influencias de tierras interiores que actúan como agentes de cambio en las sociedades depredadoras transformándolas en productoras cuando el medio ambiente es favorable; sin embargo, en la costa de nuestro interés, las grandes transformaciones quedan limitadas por las condiciones del medio. La agricultura es imposible dentro de la costa de interfluvio, sin embargo se asimilan los productos cultivados en valles y oasis, y se incorpora la tecnología cerámica, a telary metalurgia [...] Las poblaciones formativas se asentaron preferentemente en ecologías favorables a las prácticas hortícolas, la sedentarización en aldeas y otros rasgos que caracterizan a este período como se ha demostrado a través de diversas investigaciones en los valles de Arica [...]. Sin embargo en la costa desértica de interfluvio, la presencia de comunidades formativas es escasa." (Moragas 1995: 68).

Sin duda, estas apreciaciones remiten a las conclusiones de Núñez (1971) sobre el desarrollo costero de la desembocadura del Loa y Caleta Huelén, minimizando las evidencias de complejidad local y enfatizando los efectos civilizatorios de las poblaciones altiplánicas que serían las responsables de las expresiones de cambio económico y social, desplazando a las comunidades marítimas a una posición más bien marginal, limitadas al ambiente hiperárido de este litoral y dependientes de los logros agrícolas del interior. Sin embargo, nuestra evaluación indica que esa complejidad no puede ser reducida a esos logros agrícolas, ni determinada por la penetración altiplánica, sino que debe ser entendida desde su propia dinámica interna; obviamente, tampoco aislada de lo que ocurre a lo largo del Loa ni del resto de los Valles Occidentales. Desde la alfarería, al menos en su comportamiento tipológico, depositacional y funcional, no es posible establecer vínculos tan directos ni absolutos con esas variables de cambio. La cerámica implementada por los grupos costeros durante el Formativo no posee una identidad estilística ni tecnológica con los desarrollos altiplánicos. Tampoco alude a un uso referido a la introducción de los 
alimentos cultivados en términos de su procesamiento culinario. Al contrario, si exhibe una vinculación con aquello, pareciera ser en términos más simbólicos y con una carga ritual asociada al encuentro social y funerario, manifiesta en la alta proporción de potes para llevar, presentar y servir, en el ámbito doméstico, de la movilidad y sobre todo ceremonial.

Lo anterior indica un proceso de exploración y explotación creciente del borde costero por parte de las comunidades bajo un sistema fragmentado con núcleos en zonas de desembocadura donde convergerían estacionalmente y con múltiples fines a partir de los cuales se dispersarían por el litoral e incluso hacia el interior en diversos momentos. De acuerdo a ello, es lógico encontrar en torno a la desembocadura del Loa, desde Chipana y al sur de Caleta Huelén una notable concentración de cementerios de túmulos y fosas que remiten justamente a esta época (Núñez 1971; Moragas 1995; Agüero y Uribe $2008 \mathrm{Ms}$ ). En suma, las poblaciones se mantendrían en una constante y alta movilidad desde inicios hasta finales del Formativo, seguramente bajo el mismo patrón arcaico, con asentamientos pasajeros y una baja densidad depositacional, pero abarcando un territorio cada vez mayor por parte de aquellas que acceden a y/o producen alfarería. Bajo este supuesto, hacia el Intermedio Tardío ese mismo patrón sufriría una fuerte transformación, potenciando cada vez más ciertos puntos en plena costa arreica y sin tanta dependencia con respecto a las desembocaduras de ríos (Adán y Urbina 2004 Ms; Uribe et al. 2007).

En este sentido, y con el propósito de mejorar nuestro acercamiento a esta particular complejidad que representan los desarrollos costeros de Iquique, donde se encuentran hasta ahora las manifestaciones más tempranas de alfarería en Tarapacá, creemos que la investigación debe continuar el camino trazado por algunos asertos que nos anteceden y que han sido bien expuestos para la región:

"En general, es posible aceptar estos planteamientos, aunque creemos merecen un mayor análisis para los eventos de la costa árida. Por su carácter árido y de enclaves aislados, bastante diferentes de los sistemas de costa-valle fértil como Arica o desembocadura del río Loa, aún resulta difícil definir las poblaciones originales de rango agrocerámico en la costa sur de Iquique, pero es posible sostener que poblaciones de una larga tradición marítima [...] persisten sin mayores variaciones desde etapas anteriores a las comunidades "Chinchorro" $y[\ldots]$ se sostienen sobre procesos de movilidad horizontal y transversal [...]" (Sanhueza 1985:57).

Nuestro análisis cerámico ha intentado avanzar justamente en esta perspectiva, al valorizar esa situación y conceptualizar esta forma de vida como parte de una complejidad propia de las poblaciones marítimas del centro sur andino, y que recién empezamos a conocer.

Agradecimientos Este trabajo es resultado del proyecto FONDECYT 1080458 , pero también integra la información obtenida con anterioridad en los proyectos FONDECYT 1030923 y 1990168. Al respecto, agradezco a las colegas Leonor Adán, Carolina Agüero y Patricia Ayala por su apoyo y permitirme utilizar datos que son producto del trabajo conjunto. Asimismo, a todos los colegas, estudiantes y amigos que han participado en las temporadas de terreno y trabajo en laboratorio, así como a Paulina Chávez por las ilustraciones. También agradezco los comentarios y observaciones hechas al manuscrito, los que contribuyeron a mejorar su calidad. Finalmente, gracias a las comunidades locales de Tarapacá por su colaboración y comprensión a la investigación científica. 


\section{* Referencias citadas}

AdÁn, L. y S. Urbina, 2004 Ms. Historia arquitectónica de la localidad de Pisagua (I región, Chile): Una tradición olvidada en los períodos tardíos del área Pica-Tarapacá. Ponencia presentada en el XV Congreso Nacional de Arqueología Argentina, Río Cuarto.

AgüEro, C. y M. Uribe, 2008 Ms. Tumbas y túmulos en la costa y pampa de Tarapacá: Explicando el período Formativo en el norte de Chile (Andes Centro Sur). Ponencia presentada en el II Congreso de la Red Europea de Estudios AmerindiosRitual Ameritas, Lovaina la Nueva.

Agüero, C., M. Uribe, P. Ayala y B. Cases, 1999. Una aproximación arqueológica a la etnicidad y el rol de los textiles en la construcción de la identidad cultural en los cementerios de Quillagua (norte de Chile). Gaceta Arqueológica Andina 25: 167-198.

Agüero, C., M. Uribe, P. Ayala, B. Cases y C. Carrasco, 2001. Ceremonialismo del período Formativo en Quillagua, Norte Grande de Chile. Boletín de la Sociedad Chilena de Arqueología 32: $24-34$.

Agüero, C., P. Ayala, M. Uribe, C. Carrasco y B. Cases, 2006. El período Formativo desde Quillagua, Loa Inferior (norte de Chile). En Esferas de interacción prehistóricas y fronteras nacionales modernas: Los Andes sur centrales, H. Lechtman (Ed.), pp. 449502. Instituto de Estudios Peruanos, Lima.

Aufderheide, A., M. Kelley, M. Rivera, L. Gray, L. Tieszen, E. Iversen, R. Krouse y A. Carevic, 1994. Contributions of chemical dietary reconstruction to the assessment of adaptation by ancient highland immigrants (Alto Ramírez) to coastal conditions at Pisagua, North Chile. Journal of Archaeological Science 21: 515-524.

Ayala, P., 2001. Las sociedades formativas del Altiplano Meridional y su relación con el Norte Grande de Chile. Estudios Atacameños 21: 7-39.

Ayala, P. y M. URibe, 2003. La cerámica Wankarani y una primera aproximación a su relación con el período Formativo del Norte Grande de Chile. Textos Antropológicos 14 (1): 7-30.

Ayala, P., C. Carrasco y M. Uribe, 2008. Alfarería y líticos Wankarani: Caracterización y vínculos con el Norte Grande de Chile. En Arqueología de las tierras altas, valles interandinos y tierras bajas de Bolivia. Memorias del ${ }^{e r}$ Congreso de Arqueología de Bolivia, C. Rivera (Ed.), pp. 99-114. Instituto de Investigaciones Antropológicas y Arqueológicas, Universidad Mayor de San Andrés, La Paz.
BIRD, J., 1943. Excavations in Northern Chile. Anthropological Papers of the American Museum of Natural History XXXVIII (4), Nueva York.

BARNETT, W. y J. HoopEs, 1995. The emergence of pottery. Technology and innovation in ancient societies. Smithsonian Institution Press, Washington D. C. y Londres.

Gallardo, F., L. Cornejo, R. Sánchez, B. Cases, A. Román y A. DezA, 1991. Una aproximación a la cronología y el asentamiento en el oasis de Quillagua (río Loa, II región). Actas del XII Congreso Nacional de Arqueología Chilena, vol. I2, pp. 41-6o. Temuco.

Kautz, R., T. Delaca y D. True, 1980. Constituent analysis of prehistoric pottery using $\mathrm{X}$-ray dispersive analysis: Caserones plainware. Estudios Arqueológicos 5: 21-27.

Latcham, R., 1938. Arqueología de la región atacameña. Prensas de la Universidad de Chile, Santiago.

MAVRAKIS, R., 1985. Análisis tipológico morfológico de la cerámica de Caserones (I región, Chile). Memoria para optar al título de Arqueólogo, Universidad del Norte, Antofagasta.

Meighan, C., 1980. The archaeology of Guatacondo, Chile. En Prehistoric trails of Atacama: Archaeology of Northern Chile, C. Meighan y D. True (Eds.), pp. 93-133. Monumenta Archaeologica 7, The Institute of Archaeology, University of California, Los Angeles.

Méndez-Quirós, P. y M. URibe, 2006. Análisis estratigráfico y cronología del complejo cultural Pica-Tarapacá (950-1450 DC). Actas del XVII Congreso Nacional de Arqueología Chilena, Valdivia. En prensa.

Moragas, C., 1982. Túmulos funerarios en la costa sur de Tocopilla (Cobija), II región. Chungara 9: 152-173.

1995. Desarrollo de las comunidades prehispánicas del litoral Iquique-desembocadura río Loa. Hombre y Desierto 9 (I): 65-80.

Mostny, G., 1970. La subárea arqueológica de Guatacondo. Boletín del Museo Nacional de Historia Natural XXIX (16): 271-287.

MuÑoz, I., 1989. El período Formativo en el Norte Grande (1000 AC-500 DC). En Culturas de Chile. Prehistoria. Desde sus orígenes a los albores de la Conquista, J. Hidalgo, V. Schiappacasse, H. Niemeyer, C. Aldunate e I. Solimano (Eds.), pp. 107-128. Editorial Andrés Bello, Santiago. 
2004. El período Formativo en los valles del norte de Chile y sur de Perú: Nuevas evidencias y comentarios. Chungara, Revista de Antropología Chilena vol. especial (1): 213-225.

2005. Las poblaciones de los valles costeros del área Centro Sur Andina durante los inicios del proceso aldeano (1000 AC-20o DC). En Arqueología del Desierto de Atacama. La etapa formativa en el área de Ramaditas/Guatacondo, M. Rivera (Ed.), pp. 231-258. Universidad Bolivariana, Santiago.

MuÑoz, I., R. Rocha y S. CHACón, 1991. Camarones 15. Asentamiento de pescadores correspondiente al Arcaico y Formativo (extremo norte de Chile). Actas del XI Congreso Nacional de Arqueología Chilena, vol. 2, pp. 1-24. Museo Nacional de Historia Natural, Santiago.

NúÑEz, L., 1965. Desarrollo cultural prehispánico del norte de Chile. Estudios Arqueológicos 1: 37-115.

1966. Caserones 1, una aldea prehispánica del norte de Chile. Estudios Arqueológicos 2: 25-29.

_1967-68. Figurinas tempranas del norte de Chile (provincia de Tarapacá). Estudios Arqueológicos 3-4: 85-105.

1969. El primer fechado radiocarbónico del complejo Faldas del Morro en el sitio Tarapacá 40 y algunas discusiones básicas. Actas del V Congreso Nacional de Arqueología Chilena, pp. 47-58. Museo Arqueológico de La Serena, La Serena.

1970. Algunos problemas del estudio del complejo arqueológico Faldas del Morro, norte de Chile. Abband. Berich Des Staa. Mus. Volker. Dresden Bond 31: 79-109.

- 1971. Secuencia y cambio en los asentamientos humanos de la desembocadura del río Loa en el norte de Chile. Boletín de la Universidad de Chile 112:3-25.

1982. Temprana emergencia de sedentarismo en el desierto chileno. Proyecto Caserones. Chungara 9: 80-122.

1984. Tráfico de complementariedad de recursos entre las tierras altas y el Pacífico en el área Centro Sur Andina. Tesis Doctoral, Departamento de Antropología Cultural, Universidad de Tokio, Tokio.

NúÑEz, L. y C. Moragas, 1983. Cerámica temprana en Cáñamo (costa desértica del norte de Chile): Análisis y evaluación regional. Chungara 11:31-61.

Rivera, M., 1988-89. Cerámicas tempranas de la costa norte de Chile. Paleoetnológica 5:165-172.
2002. Historias del desierto. Arqueología del norte de Chile. Editorial del Norte, La Serena.

2005. Arqueología del Desierto de Atacama. La etapa formativa en el área de Ramaditas/Guatacondo. Universidad Bolivariana, Santiago.

Rivera, M., D. Shea, A. Carevic y G. Graffam, 1995-96. En torno a los orígenes de las sociedades complejas andinas: Excavaciones en Ramaditas, una aldea formativa del Desierto de Atacama, Chile. Diálogo Andino 14/15:205-239.

SAnhueZa, J., 1985. Poblaciones tardías en playa Los Verdes, costa sur de Iquique, I región, Chile. Chungara 14:45-60.

2005. Un cementerio del período Formativo en el oasis de Pica (Desierto de Tarapacá). Boletín de la Sociedad Chilena de Arqueología 38: 31-43.

Santoro, C., 1981. Formativo Temprano en el extremo norte de Chile. Chungara 8:33-62.

2000. El Formativo en la región de valles occidentales del área Centro Sur Andina (sur Perú-norte de Chile). En Formativo sudamericano. Una revaluación, P. Lederberger-Crespo (Ed.), pp. 243-254. Ediciones Abya-Yala, Quito.

Schaedel, R.y C. Munizaga, 1957.Arqueología chilena: Contribuciones al estudio de la región comprendida entre Arica y La Serena. Centro de Estudios Antropológicos, Universidad de Chile, Santiago.

Schiappacasse, V., A. Román, I. Muñoz, A. Deza y G. Focacci, 1991. Cronología por termoluminiscencia de la cerámica del extremo norte de Chile: Primera parte. Actas XI Congreso Nacional de Arqueología Chilena, vol. 2, pp. 43-60. Museo Nacional de Historia Natural, Santiago.

Sinclaire, C., M. Uribe, P. Ayala y J. González, 1998. La alfarería del período Formativo en la región del Loa Superior: Sistematización y tipología. Actas del XIV Congreso Nacional de Arqueología Chilena, vol. 2, pp. 285-314. Copiapó.

Spahni, J. C., 1967. Recherches archéologiques a l'embochure du rio Loa (côte du Pacifique, Chili). Journal de la Société des Americanistes 56 (1): 179-239.

True, D., 1980. Archaeological investigations in Northern Chile: Caserones. En Prehistoric trails of Atacama: Archaeology of Northern Chile, C. Meighan y D. True (Eds.), pp. 139-178. Monumenta Archaeologica 7, The Institute of Archaeology, University of California, Los Angeles.

Uhle, M., 1922. Fundamentos étnicos y arqueología de Arica y Tacna. Universidad Central, Quito. 
Uribe, M., 1999. La cerámica de Arica 40 años después de Dauelsberg. Chungara 31 (2):189-228.

2002. Sobre alfarería, cementerios, fases y procesos durante la prehistoria tardía del Desierto de Atacama (800-1600 DC). Estudios Atacameños 22: 7-31.

2004. Alfarería, arqueología y metodología. Aporte y proyecciones de los estudios cerámicos del Norte Grande de Chile. Tesis de Magíster en Arqueología, Universidad de Chile, Santiago.

2006a. Sobre cerámica, su origen y complejidad social en los Andes del Desierto de Atacama. En Esferas de interacción prehistóricas y fronteras nacionales modernas: Los Andes sur centrales, H. Lechtman (Ed.), pp. 449-502. Instituto de Estudios Peruanos, Lima.

2006b. Arqueología de Pica-Tarapacá (norte de Chile): Reflexiones acerca de la complejidad y desigualdad social en los Andes Centro Sur (1000-1450 DC). Estudios Atacameños 31: 91-114.
2008 Ms. Cerámica y complejidad social en la quebrada de Tarapacá: Avances sobre el período Formativo y Horizonte Medio en el norte de Chile. Ponencia presentada en el $73^{\text {rd }}$ Annual Meeting of the Society for American Archaeology, Vancouver.

URIBE, M.y L.AdÁN, 2008. Evolución social a través de la prehistoria tardía de Pica-Tarapacá (Norte Grande de Chile). En Puentes hacia el pasado. Reflexiones teóricas en arqueología, D. Jackson, D. Salazar y A. Troncoso (Eds.), pp. 147-168. Serie Monográfica de la Sociedad Chilena de Arqueología 1, Santiago.

URIbe, M. y P. Ayala, 2004. La alfarería de Quillagua en el contexto formativo del Norte Grande de Chile (1000 AC-500 DC). Chungara, Revista de Antropología Chilena vol. especial (2): 585-597.

Uribe, M., L. Sanhueza y F. Bahamondes, 2007. La cerámica prehispánica tardía de Tarapacá, sus valles interiores y costa desértica, norte de Chile (ca. 900-1450 DC): Una propuesta tipológica y cronológica. Chungara, Revista de Antropología Chilena 39 (2): 143-170. 
